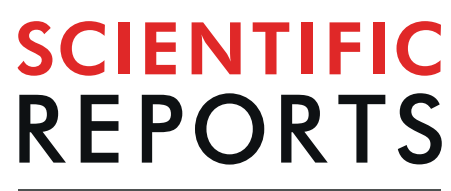

natureresearch

\title{
Hepatocyte-specific deletion of Ppara promotes NAFLD in the context of obesity
}

\author{
Marion Régnier $\mathbb{1}^{1}{ }^{1}$, Arnaud Polizzi ${ }^{1}$, Sarra Smati ${ }^{1,2}$, Céline Lukowicz ${ }^{1}$, Anne Fougerat ${ }^{1}$, \\ Yannick Lippi $\mathbb{D}^{1}$, Edwin Fouché ${ }^{1}$, Frédéric Lasserre ${ }^{1}$, Claire Naylies ${ }^{1}$, Colette Bétoulières ${ }^{1}$, \\ Valentin Barquissau ${ }^{2}$, Etienne Mouisel ${ }^{2}$, Justine Bertrand-Michel ${ }^{3}$, Aurélie Batut ${ }^{3}$, \\ Talal Al Saati ${ }^{4}$, Cécile Canlet ${ }^{1}$, Marie Tremblay-Franco ${ }^{1}$, Sandrine Ellero-Simatos ${ }^{1}$, \\ Dominique Langin $\mathbb{1}^{2,5}$, Catherine Postic ${ }^{6}$, Walter Wahli ${ }^{1,7,8}$, Nicolas Loiseau ${ }^{1}{ }^{1}$, \\ Hervé Guillou ${ }^{1 *}$ \& Alexandra Montagner ${ }^{1,2^{*}}$
}

Peroxisome proliferator activated receptor $\alpha$ (PPAR $\alpha$ ) acts as a fatty acid sensor to orchestrate the transcription of genes coding for rate-limiting enzymes required for lipid oxidation in hepatocytes. Mice only lacking Ppar $\alpha$ in hepatocytes spontaneously develop steatosis without obesity in aging. Steatosis can develop into non alcoholic steatohepatitis (NASH), which may progress to irreversible damage, such as fibrosis and hepatocarcinoma. While NASH appears as a major public health concern worldwide, it remains an unmet medical need. In the current study, we investigated the role of hepatocyte PPARo in a preclinical model of steatosis. For this, we used High Fat Diet (HFD) feeding as a model of obesity in C57BL/6 J male Wild-Type mice (WT), in whole-body Ppar $\alpha$ - deficient mice $\left(P\right.$ par $\left.{ }^{-l-}\right)$ and in mice lacking Ppar $\alpha$ only in hepatocytes (Ppar $\alpha^{h e p-l-}$ ). We provide evidence that Ppar $\alpha$ deletion in hepatocytes promotes NAFLD and liver inflammation in mice fed a HFD. This enhanced NAFLD susceptibility occurs without development of glucose intolerance. Moreover, our data reveal that non-hepatocytic PPAR $\alpha$ activity predominantly contributes to the metabolic response to HFD. Taken together, our data support hepatocyte PPAR $\alpha$ as being essential to the prevention of NAFLD and that extra-hepatocyte PPAR $\alpha$ activity contributes to whole-body lipid homeostasis.

Non alcoholic fatty liver disease (NAFLD) has become a major public health concern worldwide ${ }^{1}$. NAFLD ranges from benign steatosis to non alcoholic steatohepatitis (NASH), which may progress to irreversible damage, such as fibrosis or hepatocarcinoma. The hallmark of NAFLD is an elevated level of neutral lipids, which accumulate as lipid droplets in hepatocytes ${ }^{2}$. Although the aetiology of the disease is not fully understood, it is strongly associated with obesity and type 2 diabetes (T2D). In human NAFLD, the fatty acids that accumulate in hepatocytes originate from dietary fat $^{3,4}$, adipose tissue lipolysis and hepatic de novo lipogenesis ${ }^{3}$. In T2D, adipose tissue insulin resistance promotes lipolysis, whereas hyperglycaemia combined with hyperinsulinemia sustains hepatic de novo lipogenesis ${ }^{5}$.

Given the burden of the NAFLD epidemic, identifying molecular players that can be targeted is a rather important issue ${ }^{6,7}$. Moreover, finding drugs that may be used to treat NASH and its progression to irreversible liver disease is a so far unmet medical need to be solved ${ }^{8,9}$. Among drugs currently being tested in clinical trials

\footnotetext{
${ }^{1}$ Toxalim, INRAE UMR 1331, ENVT, INP-Purpan, University of Toulouse, Paul Sabatier University, F-31027, Toulouse, France. ${ }^{2}$ Institut National de la Santé et de la Recherche Médicale (INSERM), UMR1048, Institute of Metabolic and Cardiovascular Diseases, University of Toulouse, Paul Sabatier University, Toulouse, France. ${ }^{3}$ Metatoul-Lipidomic Facility, MetaboHUB, Institut National de la Santé et de la Recherche Médicale (INSERM), UMR1048, Institute of Metabolic and Cardiovascular Diseases, Toulouse, France. ${ }^{4}$ Service d'Histopathologie Expérimentale Unité INSERM/ UPS/ENVT-US006/CREFRE Inserm, CHU Purpan, 31024, Toulouse, cedex 3, France. ${ }^{5}$ Toulouse University Hospitals, Laboratory of Clinical Biochemistry, Toulouse, France. ${ }^{6}$ Institut National de la Santé et de la Recherche Médicale (INSERM), U1016, Institut Cochin, Paris, France. ${ }^{7}$ Lee Kong Chian School of Medicine, Nanyang Technological University Singapore, Clinical Sciences Building, 11 Mandalay Road, Nanyang, Singapore. ${ }^{8}$ Center for Integrative Genomics, Université de Lausanne, Le Génopode, Lausanne, Switzerland. *email: herve.guillou@inrae.fr; alexandra. montagner@inserm.fr
} 
are a number of molecules that activate the peroxisome proliferator activated receptors (PPARs) ${ }^{8,10}$. Three PPAR isotypes are known $(\alpha, \beta / \delta$, and $\gamma)$, and they are members of the nuclear receptor family, which act as fatty acid sensors that orchestrate transcription in response to a variety of endogenous ligands ${ }^{10}$, such as fatty acids ${ }^{11}$, fatty acid derivatives ${ }^{12}$ and phospholipids ${ }^{13}$. Once activated by the binding of these lipids, PPARs may either induce or repress the expression of their specific target genes. PPARs are influential regulators of genes involved in metabolism in different tissues ${ }^{14}$. Therefore, several pharmacological agonists have been developed, tested in preclinical models of NAFLD ${ }^{15,16}$, and are currently being either used or tested in clinical trials for the treatment of metabolic diseases, and especially NAFLD ${ }^{16}$.

PPAR $\alpha$ is the most abundant PPAR isotype in the healthy liver ${ }^{17}$ and in hepatocytes, PPAR $\alpha$ regulates the expression of thousands of genes and contributes to the remarkable metabolic flexibility of the liver ${ }^{18-21}$. PPAR $\alpha$ is particularly active during suckling ${ }^{22-24}$ and fasting ${ }^{19,20,25-28}$, two conditions in which fatty acids are a preferred source of energy for the organism. PPAR $\alpha$ is also expressed in many other tissues, including skeletal muscle ${ }^{29}$, adipose tissues $^{30-33}$, intestine ${ }^{34}$, heart ${ }^{35}$, and kidney ${ }^{36}$. Germline deletion of Ppar $\alpha$ renders mice susceptible for many metabolic defects including obesity ${ }^{37}$, steatosis ${ }^{37-39}$, hepatic inflammation ${ }^{40}$ and steatohepatitis ${ }^{41}$, but not diabetes $^{42,43}$. We have shown recently that a hepatocyte-specific deletion of Ppar $\alpha$ induces spontaneous steatosis in aging mice and blunts fasting-induced ketogenesis ${ }^{19,20}$. Moreover PPAR $\alpha$ is required for the expression of fibroblast growth factor 21 (FGF21) ${ }^{44,45}$, a liver-derived hormone with many endocrine ${ }^{46}$ and hepatoprotective functions ${ }^{47,48}$.

In the present study, we evaluated the importance of hepatocyte PPAR $\alpha$ in steatosis associated with diet-induced obesity. We provide evidence that in mice fed a high fat diet (HFD), Ppar $\alpha$ deletion in hepatocytes is sufficient to promote NAFLD. In addition, analysis of the hepatic transcriptome, lipidome, and metabolome, demonstrated that extrahepatic PPAR $\alpha$ activity significantly contributes to metabolic homeostasis in response to HFD consumption.

\section{Results}

Hepatic and total Ppar $\alpha$ deficiencies dissociate HFD-induced obesity and fatty liver from glucose intolerance. Male mice from different genotypes, namely wild-type (WT), germline Ppar $\alpha$-null $\left(P_{p a r \alpha}{ }^{--}\right)$and hepatocyte-specific Ppar $\alpha$-null $\left(\right.$ Ppard $\left.^{\text {hep----}}\right)$, were fed a low-fat diet (10\% fat, CTRL) or a HFD $\left(60 \%\right.$ fat) at 8 weeks of age for 10 weeks at thermoneutrality $\left(30^{\circ} \mathrm{C}\right)$. At the beginning of the experiment, the $P$ par $\alpha^{-/-}$mice were already significantly heavier than the WT and Ppar $\alpha^{\text {hep-l-}}$ mice (Fig. 1a). All mice, independently of the genotype became overweight and gained approximately $15 \mathrm{~g}$ in response to HFD consumption (Fig. 1a,b). Moreover, unlike WT and Ppard ${ }^{\text {hep---}}$ mice, $P$ par $\alpha^{-/-}$mice on CTRL diet also gained significant body weight. Therefore, $P$ par ${ }^{-1-}$ mice became more overweight than $P$ pard ${ }^{\text {hep-l- }}$ and WT mice at thermoneutrality. In CTRL mice, oral glucose tolerance (OGTT) tested after 10 weeks of HFD feeding was similar regardless of the genotype (Fig. 1c,d). In the HFD-fed groups, WT mice became glucose intolerant whereas Ppard ${ }^{\text {hep-I- }}$ and $P$ par $\alpha^{-/-}$mice were protected against this intolerance (Fig. 1c,d). These results are consistent with fasted glucose levels that increased in response to HFD only in WT mice, but not in Ppara ${ }^{\text {hep-/- }}$ or Ppard ${ }^{-/-}$mice (Fig. 1e). Therefore, HFD feeding leads to fasting hyperglycaemia and glucose intolerance in $W T$ mice, but not in Ppard $^{\text {hep-l- }}$ and Ppard $^{-1-}$ mice.

Different biochemical analyses were performed in plasma from fed animals (Fig. 1f). Total cholesterol, LDL-cholesterol, and HDL-cholesterol tended to increase in response to HFD diet in all three genotypes. However, we found that levels of the 3 lipid parameters were higher in the plasma of $P$ para ${ }^{\text {hep-l- }}$ mice than plasma from WT and $P p a r \alpha^{-1-}$ mice. Triglycerides were elevated in Ppar ${ }^{-1-}$ mice fed the CTRL diet and the HFD diet. Triglycerides were elevated in response to HFD only in Ppard ${ }^{\text {hep-I- }}$ mice, but were lower in HFD-fed Ppara ${ }^{-/-}$ mice compared to control diet-fed $P$ par $\alpha^{-1-}$ mice. Taken together, our results show that both hepatocyte-specific and whole-body deletions of Ppara promote obesity, which is dissociated from glucose intolerance in mice housed at thermoneutrality and fed a HFD.

Hepatic and total Ppara deficiencies promote liver steatosis, inflammation, and injury in HFD-induced obesity. First, we performed histological analysis in order to investigate whether the lack of Ppar $\alpha$ either globally or liver specific was associated with changes in liver integrity (Fig. 2a). We observed that Ppard $^{\text {hep-l- }}$ and Ppard ${ }^{-/-}$mice developed steatosis upon CTRL diet feeding. In HFD, steatosis in Ppar $\alpha^{\text {hep }}{ }^{-1-}$ and $P_{\text {pard }}{ }^{-1-}$ mice was much more severe than for WT mice, which is in agreement with their respective liver weight (Fig. 2a,b). To better characterize liver injury, we used the NAFLD activity scoring (NAS) ${ }^{49}$ based on the severity of NAFLD and the degree of inflammation (Fig. 2c). This NAS revealed that Ppar $\alpha^{\text {hep-l-}}$ and Ppard $^{-1-}$ mice fed a HFD exhibited increased lipid droplet deposition in the liver (Fig. 2a,c), which is confirmed by measurement of triglyceride liver content (Fig. 2e). NAS and inflammation scoring also revealed that HFD did not significantly increase hepatic inflammation in WT mice contrarily to both Ppard ${ }^{\text {hep-l- }}$ and Ppar ${ }^{-/-}$mice for which at least $75 \%$ of mice presented a NAS higher or equal to 7 (Fig. 2c,d). In agreement with increased inflammation, HFD significantly increased plasma markers of liver injury (ALT and AST) in Ppard ${ }^{-1-}$ and Ppard ${ }^{\text {hep-l- }}$ mice (Fig. 2f).

Gene expression profile in WT, Ppara ${ }^{\text {hep-I- }}$, and Ppara ${ }^{-1-}$ mice in response to HFD-induced obesity. Next, we evaluated the hepatic transcriptome expression pattern in response to HFD using microarrays (details of the experiment and results from the microarray are available in Gene Expression Omnibus database by the name GSE123354). Overall, we identified a total of 8860 probes corresponding to 7173 HFD sensitive genes in at least one of the three genotypes (based on adjusted p-value; FDR $<5 \%$, Fig. 3). Hierarchical clustering of genes highlighted 12 clusters showing specific gene expression profiles according to the experimental conditions (Fig. 3a). Four of them (clusters 1, 4, 11 and 12) showed a typical pattern in Ppar ${ }^{-1-}$ mice compared to $P$ pard ${ }^{\text {hep-I- }}$ and WT mice regardless of diet. Genes from cluster 1 and 4 were up-regulated in $P_{p a r \alpha^{-/-}}$in 

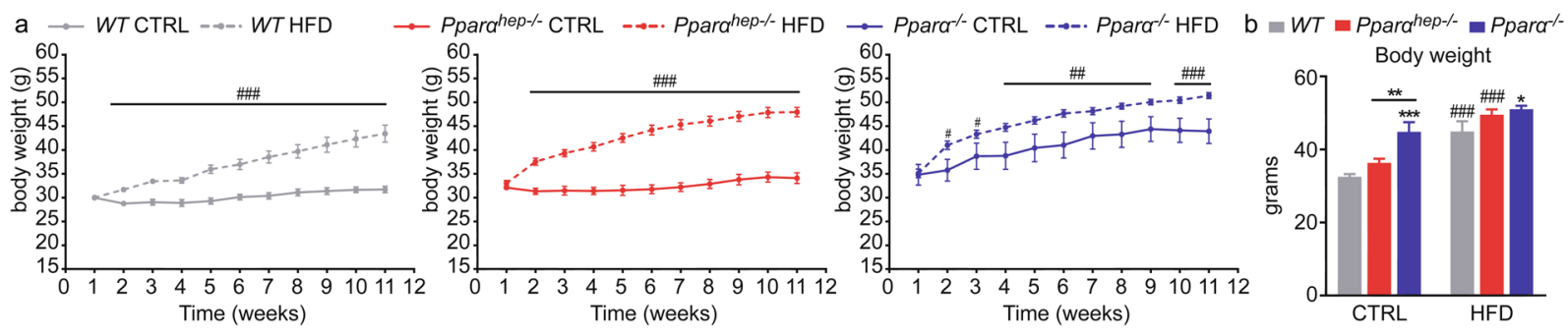

C $\rightarrow$ WT CTRL $\rightarrow$ WT HFD
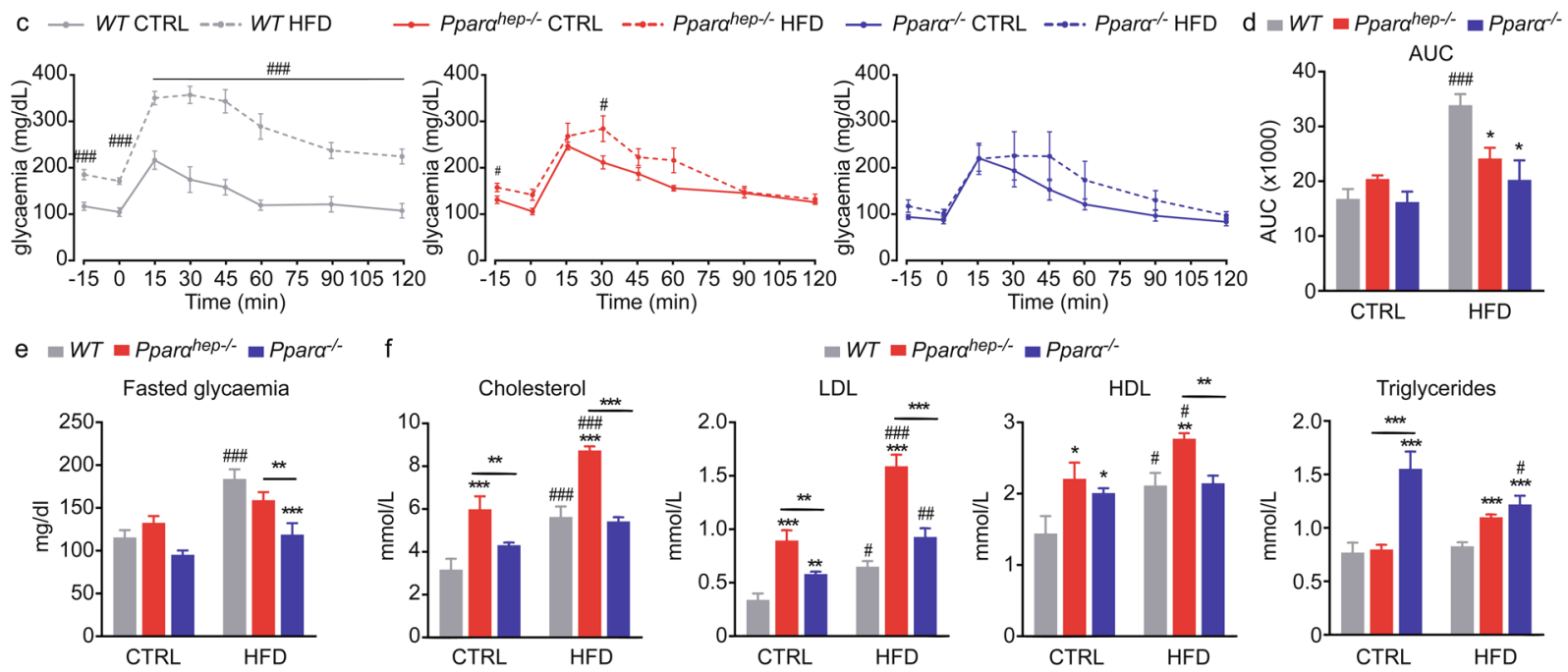

Figure 1. Hepatic and total Ppar $\alpha$ deficiency does not promote glucose intolerance in HFD- induced obesity. WT, Ppara $\alpha^{\text {hep-l-}}$, and Ppard ${ }^{-/-}$mice were fed a control diet (CTRL) or a HFD for 10 weeks at $30^{\circ} \mathrm{C}$ (thermoneutrality). (a) Body weight gain determined every week during the experiment. (b) Body weight at the end of the experiment. (c) Blood glucose measured during the oral glucose tolerance test $(2 \mathrm{~g} / \mathrm{kg}$ of body weight). (d) Area under the curve obtained after the oral glucose tolerance test. (e) Quantification of fasted glycaemia. (f) Plasma cholesterol (total, HDL, and LDL) and triglyceride plasma levels. Data represent mean \pm SEM. \#, significant diet effect and $*$, significant genotype effect. ${ }^{\#}$ or $* \mathrm{p} \leq 0.05$; \#\# or $* * \mathrm{p} \leq 0.01$; $^{\# \#}$ or $* * * \mathrm{p} \leq 0.001$.

comparison to $P$ para ${ }^{\text {hep-I- }}$ and WT mice. On the contrary, genes from cluster 11 and 12 were down-regulated in Ppar $^{-1-}$. The analysis of gene categories differentially expressed in Ppar $^{-1-}$ as compared to Ppard ${ }^{\text {hep-l- }}$ and WT mice highlight the down-regulation of genes associated with PPAR signalling and metabolic homeostasis (Supplementary Figure 1).

Cluster 8 highlighted genes common between $P_{p a r \alpha^{-/-}}$and $P$ pard ${ }^{\text {hep-l- }}$ mice but distinct from WT mice regardless of diet. Interestingly, HFD influences the liver transcriptome in a genotype-specific manner (clusters 2, 5, 6, 9 and 10). The sparse Partial Least Square Discriminant Analysis (sPLS-DA) shows that, although Ppar ${ }^{-/-}$ mice liver gene expression profile is clearly different from others, there is also a marked effect of the diet in mice from the 3 genotypes (Fig. 3b). Moreover, the gene expression profile in the liver of HFD-fed mice revealed that:

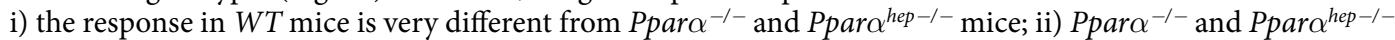
mice have a closer response to HFD (Fig. 3c). Representative qPCR measurements of different gene expression are in line with the microarray analysis (Fig. 3d). The expression of Vnn1, encoding a liver-enriched oxidative stress sensor involved in the regulation of multiple metabolic pathways ${ }^{50}$, was identified as an HFD-responsive gene specific to the WT mice. Fmo3, involved in trimethylamine $\mathrm{N}$-oxide (TMAO) production, was identified as an HFD-induced gene specifically in $\mathrm{Ppar \alpha}^{-/-}$mice. HFD increases the expression of collagen Colla1 in the absence of hepatocyte-specific or whole-body Ppar $\alpha$ but not in WT mice. Lastly, Ppar- $\gamma 2$ was identified as an HFD-responsive gene common to the three mouse genotypes. We counted 354 hepatic genes responsive to HFD common to the three mouse genotypes (Fig. 3e). These genes are mostly involved in metabolic responses to HFD which do not depend on PPAR $\alpha$ (Supplementary Figure 2).

PPAR $\alpha$-dependent changes in hepatic gene expression profiles in response to HFD-induced obesity. We next analysed the genes dependent on Ppar $\alpha$. A large group of 1749 Differentially Expressed Genes (DEGs) includes 922 genes significantly up-regulated and 827 significantly down-regulated by HFD feeding only in WT mice (Fig. 4a). Examples of these genes include well-established PPAR $\alpha$ targets, such as Cyp4a14, Acot3, Acot2, and Fitm1 (Fig. 4b), and 8 categories of genes involved in metabolism (Fig. 4c) with up-regulated expression in response to a HFD only in WT mice. However, we also identified five KEGG categories down-regulated in response to HFD specifically in WT mice. These categories relate to RNA transport, ribosome activity and protein processing (Fig. $4 \mathrm{~d}$ ). 
a

CTRL

HFD
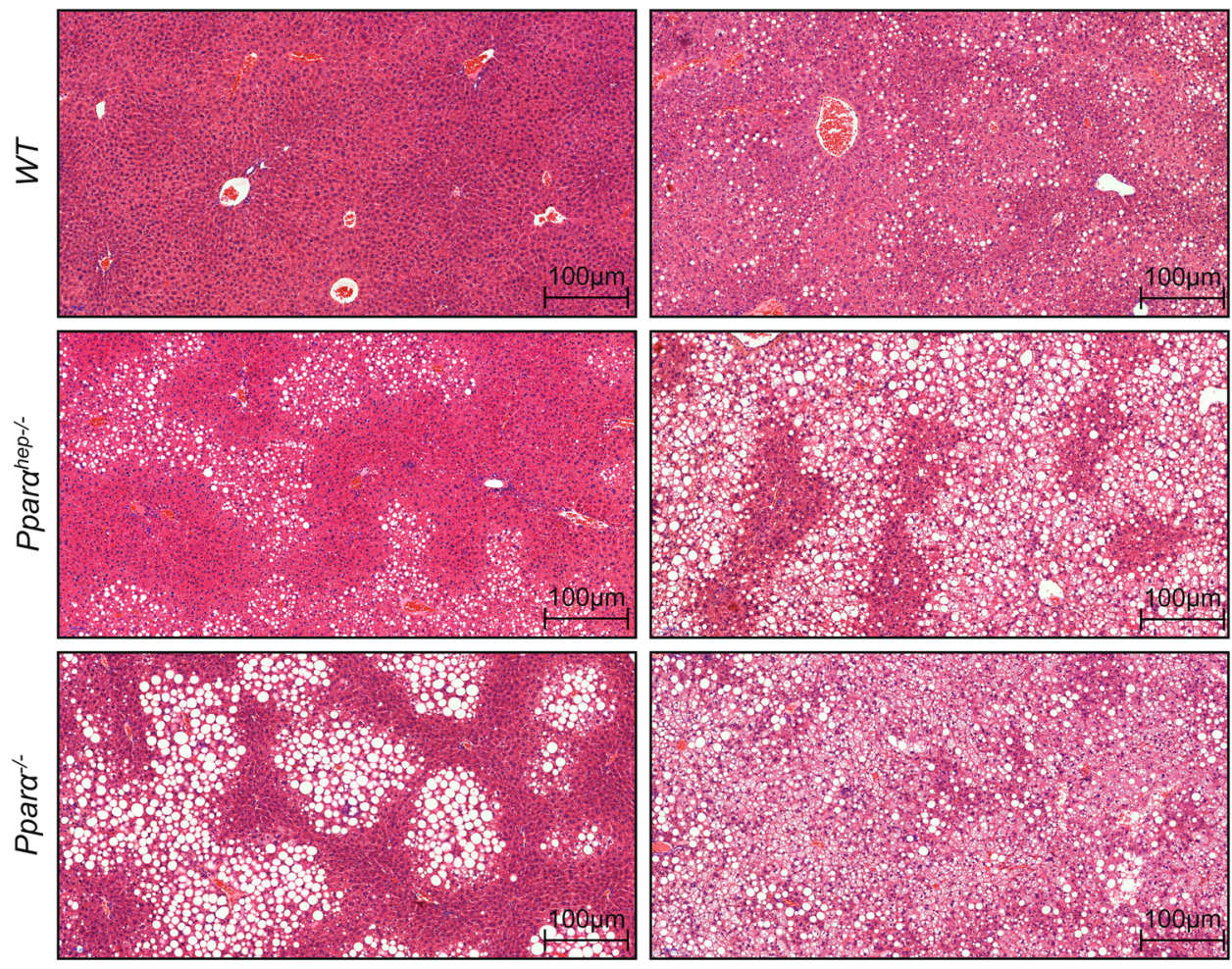

b

C

Liver weight / Body weight

NAS
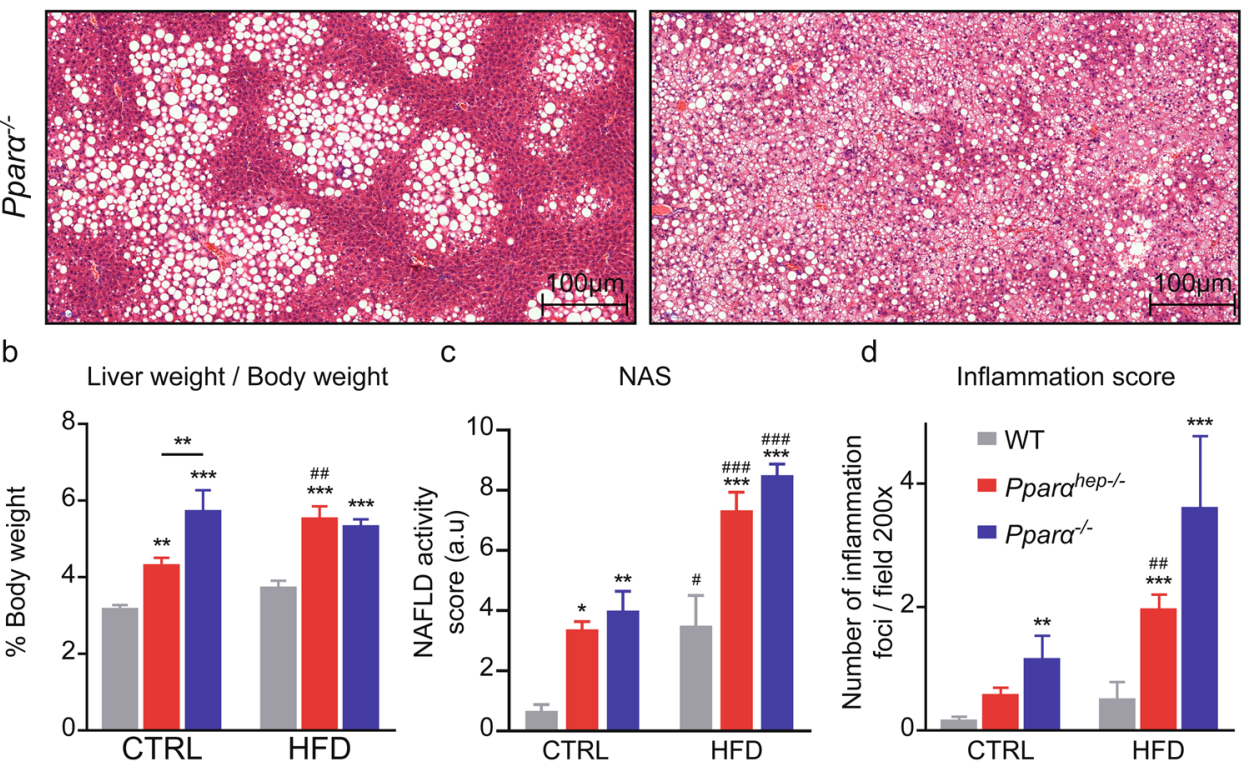

d

Inflammation score
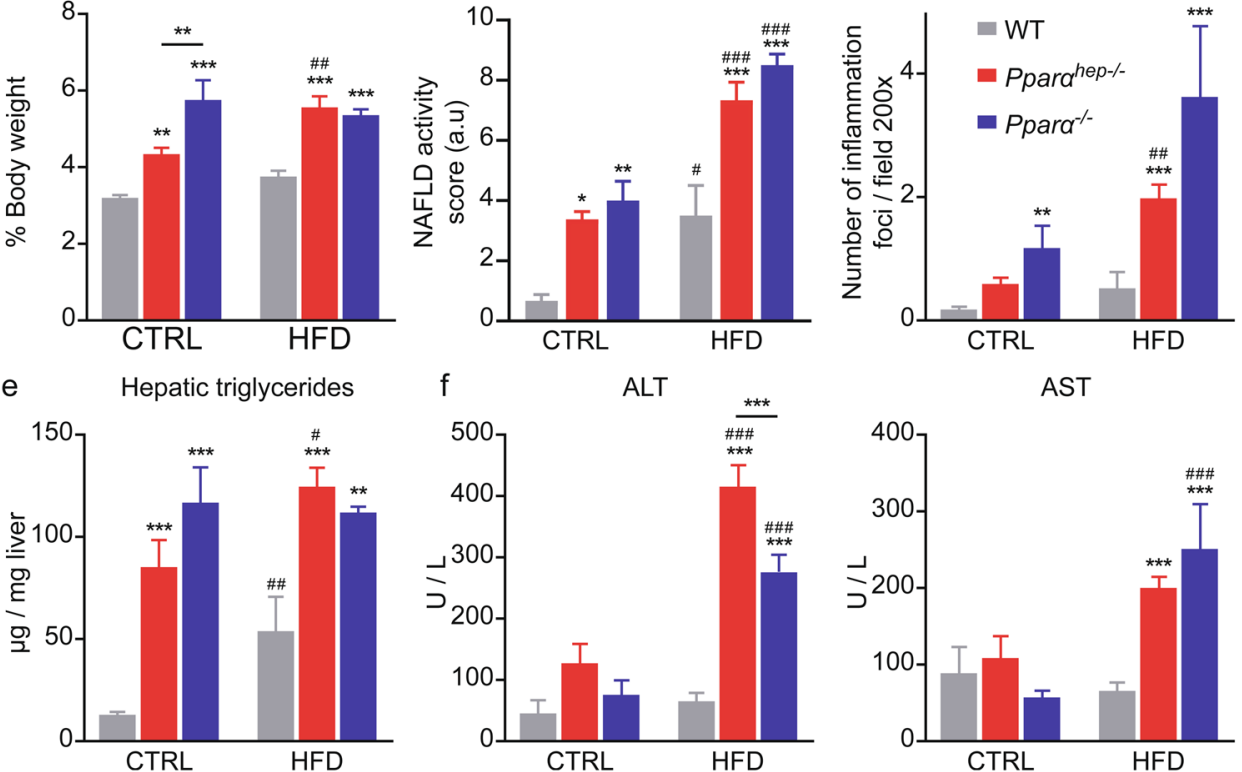

CTRL

AST

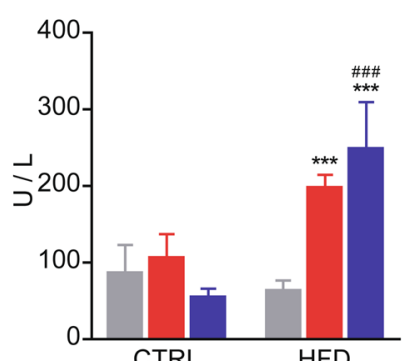

Figure 2. Hepatic and total Ppar $\alpha$ deficiency promote liver steatosis and inflammation in HFD-induced obesity. WT, Pparq ${ }^{\text {hep-l- }}$, and Ppard ${ }^{-/}$mice were fed a control diet (CTRL) or a HFD for 10 weeks at $30^{\circ} \mathrm{C}$ (thermoneutrality). (a) Representative pictures of Haematoxylin and Eosin staining of liver sections. Scale bars, $100 \mu \mathrm{m}$. (b) Liver weight as a percentage of body weight. (c) NAFLD activity score (NAS). (d) Histological scoring of inflammation foci in 10 distinct areas at $200 \times$. (e) Quantification of hepatic triglycerides (f) Plasma ALT and AST. Data represent mean \pm SEM. \#, significant diet effect and *, significant genotype effect. * or

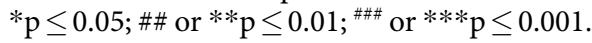

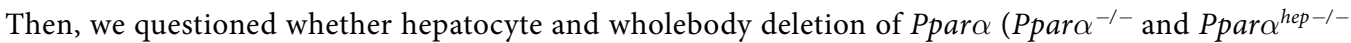
mice) induces overlapping responses in HFD-induced obesity. We identified a group of DEGs including 337 and 349 genes significantly up-regulated or down-regulated, respectively, by HFD feeding in both $P_{p a r \alpha^{-/}}$and 
a

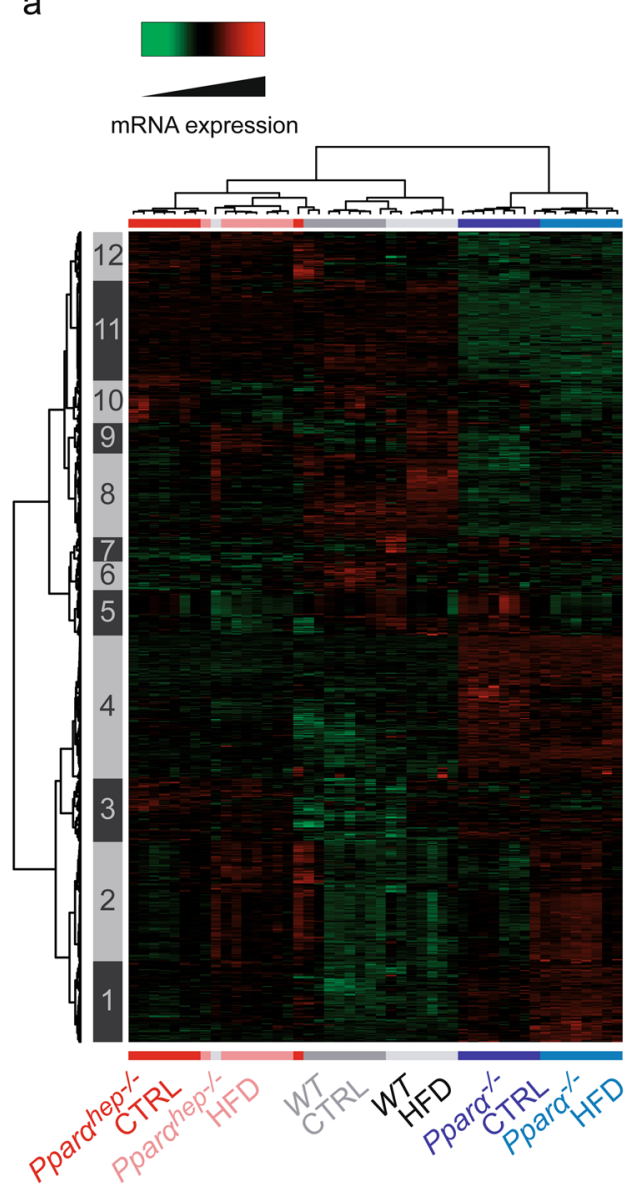

b

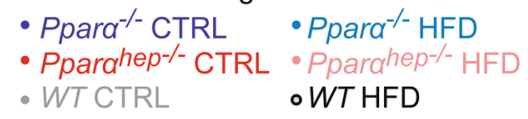

sPLS-DA: individuals plots

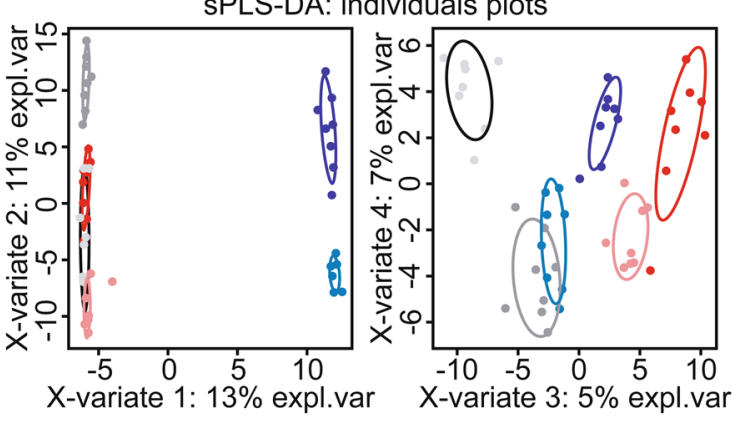

C

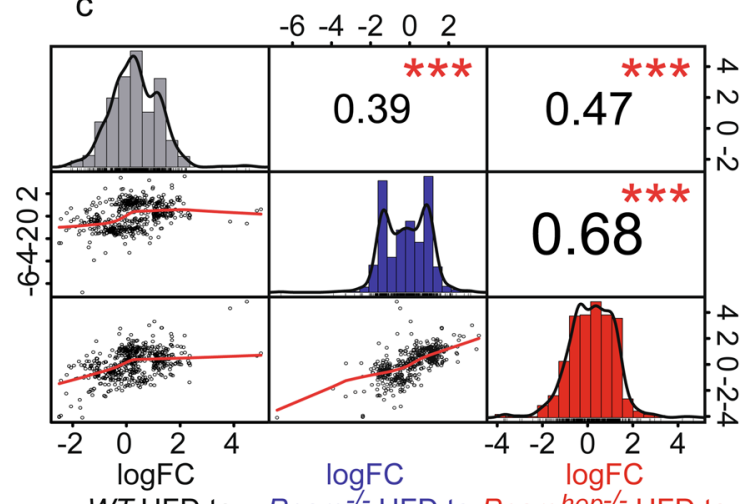

WT HFD to Ppara ${ }^{-/-}$HFD to Pparahep ${ }^{-/-}$HFD to WT CTRL Ppara ${ }^{-/-}$CTRL Pparahep-/- CTRL

d
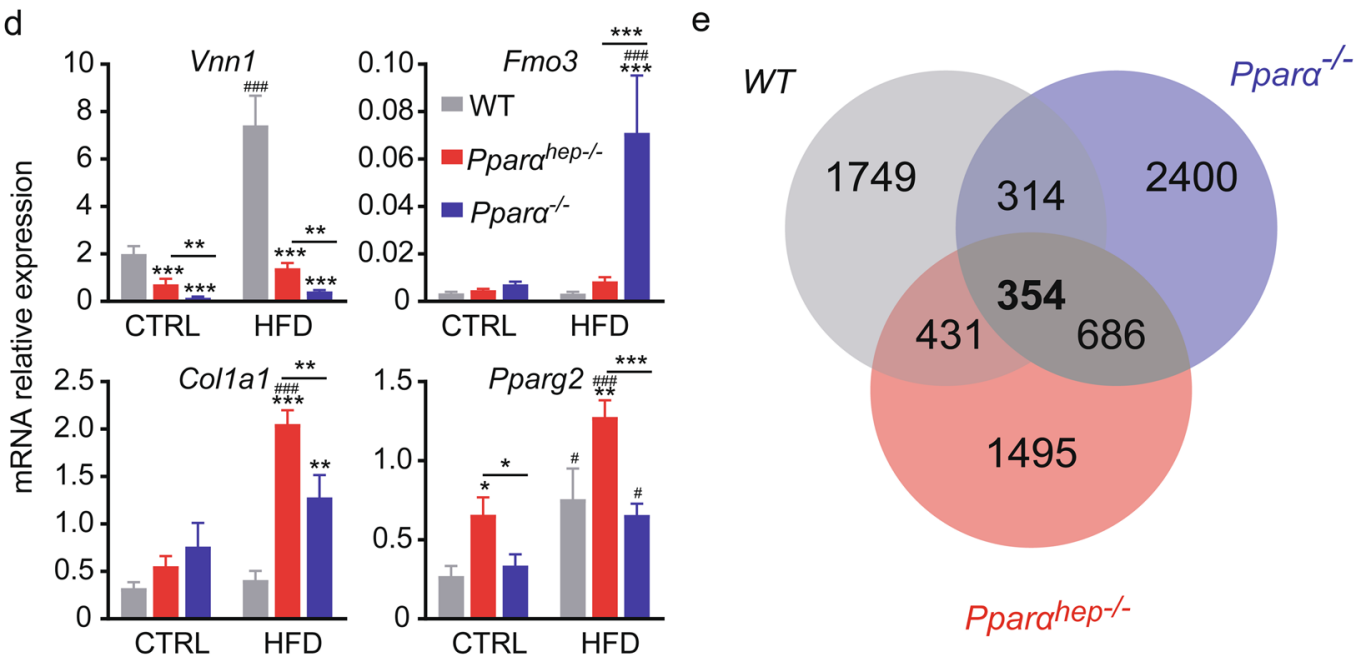

Pparahep-/-

Figure 3. Analysis of the liver transcriptome in WT, $P$ para ${ }^{\text {hep-l-}}$, and $P p a r \alpha^{-/-}$mice in response to HFD. WT, $P$ par $\alpha^{\text {hep-l-}}$, and $P$ par ${ }^{-1-}$ mice were fed a control diet (CTRL) or a HFD for 10 weeks at $30^{\circ} \mathrm{C}$ (thermoneutrality). A transcriptomic analysis performed with liver samples from WT, $P$ para ${ }^{\text {hep-l-}}$, and Ppar $^{-1-}$ exposed or not exposed to HFD ( $\mathrm{n}=8 \mathrm{mice} /$ group) revealed 7173 differentially regulated genes $(\mathrm{FDR}<5 \%)$. (a) Heat map of microarray expression data from 7173 regulated genes. Red and green indicate values above and below the mean averaged centred and scaled expression values (Z-score), respectively. Black indicates values close to the mean. According to the probe clustering (left panel), 12 gene clusters exhibited specific gene expression profiles. (b) sPLS-DA representing the 7173 differentially expressed genes from the microarray. (c) Correlation analysis between either WT, Ppard ${ }^{\text {hep-l--}}$, and $P p a r \alpha^{-/-}$mice for the effect of HFD. (d) Relative hepatic expression of Vnn1, Fmo3, Colla1 and Ppar 22 quantified by qPCR. Data represent mean \pm SEM. \#, significant diet effect and *, significant genotype effect. \# or *p $\leq 0.05$; \#\# or **p $\leq 0.01$; \#\#\# or $* * * \mathrm{p} \leq 0.001$. (e) Venn diagrams comparing the number of genes significantly regulated under HFD in the livers of $W T, P_{\text {pard }}^{\text {hep-l- }}$, and Ppard $^{-1-}$ mice at adjusted p-value $<0.05$. 
a

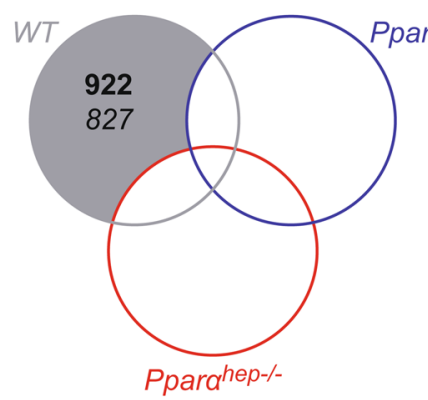

b

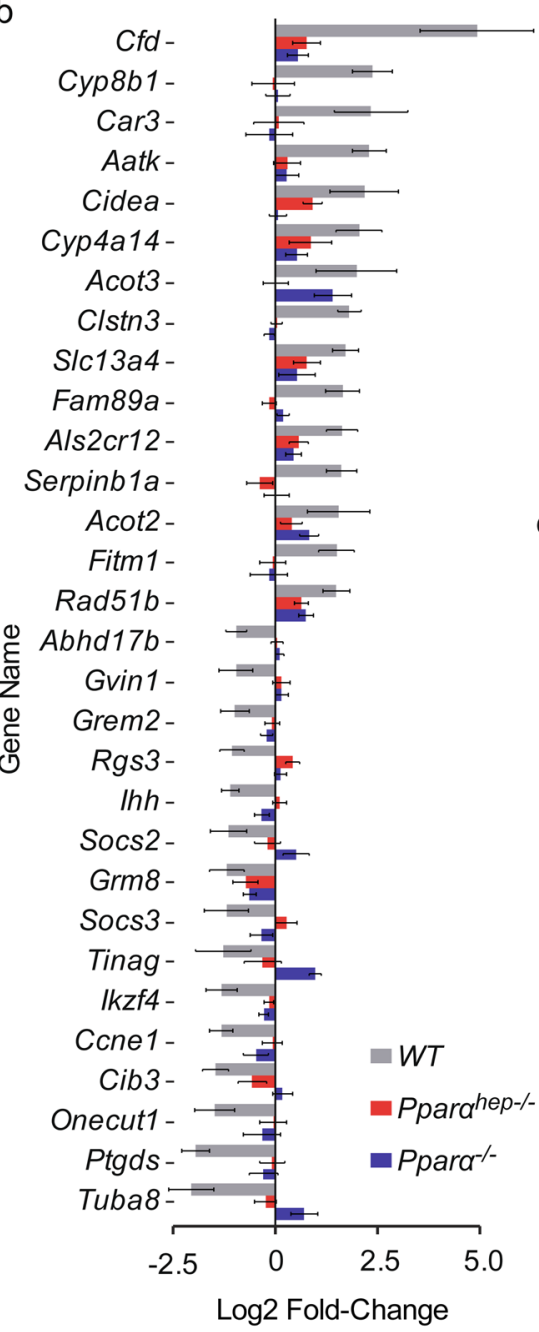

9 KEGG categories up-regulated in response to HFD specifically in WT

\begin{tabular}{lcc}
\hline Pathway description & Genes & p-value \\
\hline Metabolic pathways & 109 & $1.47 \mathrm{e}-14$ \\
Peroxisome & 16 & $2.36 \mathrm{e}-05$ \\
Thermogenesis & 25 & $7.48 \mathrm{e}-05$ \\
Biosynthesis of unsaturated FA & 9 & 0.00013 \\
Glyoxylate and dicarboxylate metabolism & 9 & 0.00017 \\
FA elongation & 8 & 0.00052 \\
Steroid biosynthesis & 7 & 0.00060 \\
Val, Leu and lleu degradation & 10 & 0.0017 \\
Retrograde endocannabinoid signaling & 15 & 0.0084 \\
\hline
\end{tabular}

d

5 KEGG categories down-regulated in response to HFD specifically in WT

\begin{tabular}{lcc}
\hline Pathway description & Genes & p-value \\
\hline Ribosome & 30 & $2.84 \mathrm{e}-14$ \\
RNA transport & 18 & 0.00056 \\
Ribosome biogenesis in eukaryotes & 12 & 0.00057 \\
Protein processing in endoplasmic reticulum & 16 & 0.0029 \\
mRNA surveillance pathway & 11 & 0.0074 \\
\hline
\end{tabular}

Figure 4. PPAR $\alpha$-independent changes in hepatic gene expression profiles in response to HFD.

WT, $P$ pard ${ }^{\text {hep-l-}}$, and $P$ par $\alpha^{-1-}$ mice were fed a control diet (CTRL) or a HFD for 10 weeks at $30^{\circ} \mathrm{C}$

(thermoneutrality). (a) Venn diagram presenting the number of hepatic genes over-expressed (bold) and downregulated (regular) in response to HFD in WT, Para $^{\text {hep- }}{ }^{--}$, Ppar $^{-1-}$ mice (FDR $<5 \%$ ) (b) Grey bars represent the top 15 specifically induced and repressed genes between WT exposed to CTRL diet and WT exposed to HFD. Red and blue bars represent the profile in Ppard ${ }^{h e p-I-}$ and $P p a r \alpha^{-1-}$ mice, respectively. (c) Gene Ontology (GO) enrichment analysis ( $\mathrm{p} \leq 0.01$ ) of KEGG categories based on functional interactions specifically downregulated in $W T$ mice fed a HFD using the String database. (d) Gene Ontology (GO) enrichment analysis (adjusted $p$-value; $\mathrm{p} \leq 0.01$ ) of KEGG categories (based on functionally interactions) up-regulated in WT mice fed a HFD the using string database.

Ppard $^{\text {hep-l- }}$ mice (Fig. 5a). Gene category analysis did not reveal any functions related to the 349 down-regulated genes by HFD feeding in $P$ par $\alpha^{-1-}$ or $P$ par $\alpha^{\text {hep-l- }}$ mice. However, gene category analysis highlighted the functions related to the 337 genes significantly up-regulated by HFD feeding in both $P$ par ${ }^{-/-}$and $P$ pard ${ }^{\text {hep }-/-}$ mice 
a
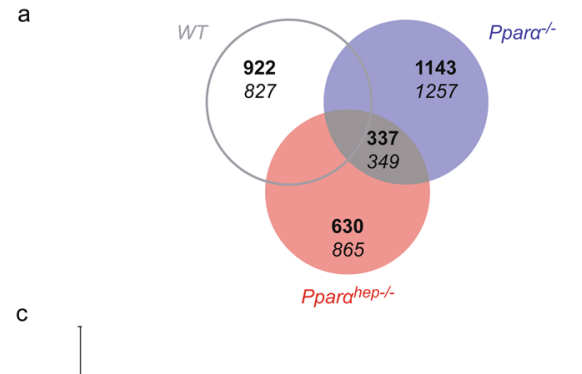

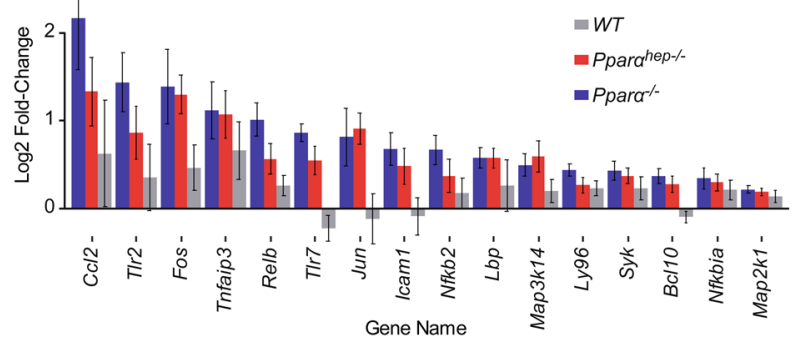

b

12 KEGG categories up-regulated in response to HFD specifically in Ppara ${ }^{-/}$and in Pparahep-- $(p<0.01)$

Pathway description Genes p-value

Lysosome $16 \quad 1.61 \mathrm{e}-09$

Osteoclast differentiation

NF-Kappa B signaling pathway

TNF signaling pathway

TLR signaling pathway

Chagas disease

Phagosome

Rheumatoid arthritis

Leishmaniasis

Epstein-Barr virus infection

$B$ cell receptor signaling

\begin{tabular}{lll} 
Influenza A & 9 & 0.00825 \\
\hline
\end{tabular}

$13 \quad 1.08 \mathrm{e}-06$

$\begin{array}{ll}10 & 2.67 \mathrm{e}-05 \\ 10 & 0.00011\end{array}$

$9 \quad 0.000366$

90.000366

$11 \quad 0.000373$

$8 \quad 0.000385$

$7 \quad 0.000625$

$10 \quad 0.00825$

$6 \quad 0.00825$

Figure 5. Hepatocyte PPAR $\alpha$ prevents liver inflammatory gene expression in response to HFD. WT, Ppara ${ }^{\text {hep-I-- }}$, and $P$ par $\alpha^{-/-}$mice were fed a control diet (CTRL) or a HFD for 10 weeks at $30^{\circ} \mathrm{C}$ (thermoneutrality). (a) Venn diagram highlighting the number of hepatic genes over-expressed (bold) and down-regulated (regular) in response to HFD specifically in both $P_{p a r \alpha^{h e p-l-}}$ and Ppard ${ }^{-1-}$ mice (FDR $<5 \%$ ). (b) Gene Ontology (GO) enrichment analysis (adjusted p $\leq 0.01$ ) of KEGG categories specifically up-regulated in both $P$ pard ${ }^{\text {hep-l- }}$ and $P$ pard ${ }^{-1-}$ mice fed a HFD. (c) Gene expression profile of genes identified as being involved in NF-kappa B, TNF and TLR signalling pathways in KEGG.

(Fig. 5b), suggesting that these genes are negatively regulated by PPAR $\alpha$. Most of these categories relate to the inflammatory process, including the NF-kappa B, TNF, and TLR signalling pathways. We selected the genes directly related to these pathways using the KEGG database and the gene database network (Supplementary Figure 3) and confirmed a marked up-regulation of genes belonging to NF-kappa B, TNF, and TLR in the hepatocyte-specific or whole-body absence of Ppar (Fig. 5c), in accordance with inflammatory markers measured (Fig. 2c,d).

Specific effect of hepatocytic PPAR $\alpha$ and whole body PPAR $\alpha$ deletion on liver gene expression in response to HFD-induced obesity. The venn diagram (Fig. 3e) also reveals a large group of DEGs modulated only in $P$ par $\alpha^{\text {hep }-1-}$ mice fed a HFD compared to CTRL diet which encompassed 630 and 865 significantly up or down-regulated genes, respectively (Supplementary Figure 4). Figure 3e also defines another large group of DEGs including 1143 and 1257 genes significantly up-regulated and down-regulated, respectively, by HFD feeding only in $\mathrm{Ppar}^{-1-}$ mice (Supplementary Figure 5). This suggests that the hepato-specific and whole-body deletions of Ppara have distinct and specific consequences in the hepatic response to HFD-induced obesity.

To further investigate their specific response, we first indentified the enriched terms across hepatic genes significantly responsive to HFD feeding in Ppara ${ }^{\text {hep }-1-}$ mice only (Fig. 6a). This analysis highlights metabolic pathways as significantly enriched (Fig. 6a) and a main network (Fig. 6b) including genes related to isoprenoid metabolism and cholesterol synthesis. Second, we analyzed the enriched terms across hepatic genes significantly responsive to HFD feeding in Ppard ${ }^{-1-}$ mice but not in WT nor in Ppard $\alpha^{\text {hep-I- }}$ mice (Fig. 6c). This analysis highlight pathways related to metabolism, hemostasis and inflammation as significantly enriched (Fig. $6 c$ ) and a main network (Fig. 6d) mostly including genes related to inflammation as well as cell morphology, adhesion and migration.

Metabolic and lipidomic profiling of PPAR $\alpha$-dependent regulation of hepatic homeostasis in response to HFD. We performed unbiased hepatic metabolomic profiling of aqueous metabolites using proton nuclear magnetic resonance $\left({ }^{1} \mathrm{H}-\mathrm{NMR}\right)$. We used a projection to latent structures for discriminant analysis (PLS-DA) to investigate whether there was a separation between experimental groups of observations. A valid and robust PLS-DA model was obtained that discriminated HFD-fed Ppar ${ }^{-1-}$ mice from all other groups (Supplementary Figure 6), further supporting the role of non-hepatocytic PPAR $\alpha$ activity in liver homeostatic response to HFD.

We also performed a targeted analysis of 75 lipid species including neutral lipids (cholesterol, cholesterol esters, and triglycerides), phospholipids, and sphingolipids (Fig. 7). The relative abundance of each species in the livers of WT, Ppara ${ }^{-1-}$, and Ppara hep-/- mice fed one of the two diets (CTRL and HFD) was evaluated to determine the contribution of hepatocyte and whole body PPAR $\alpha$ activity to hepatic lipid homeostasis. The results are presented as a heatmap with hierarchical clustering (Fig. 7a), in which we observed that the samples first clustered according to the diet, demonstrating that HFD-feeding was the main discriminating factor for hepatic lipid content. We identified four main clusters of lipids with distinct profiles relative to the different experimental conditions. Lipids in cluster 1, such as the ceramides d18:1/C18:1, d18:1/C18:0, and d18:1/C26:0 (Fig. 7b), exhibit 


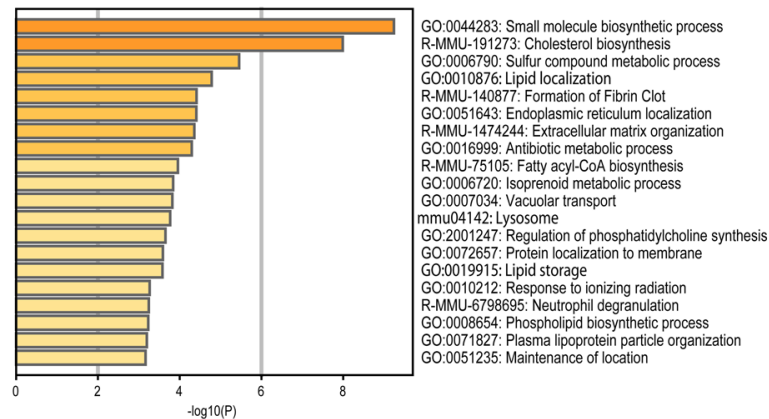

b Network of enriched terms accross HFD sensitive genes $(p<0.05)$ specifically in Ppara ${ }^{\text {hep-rt }}$

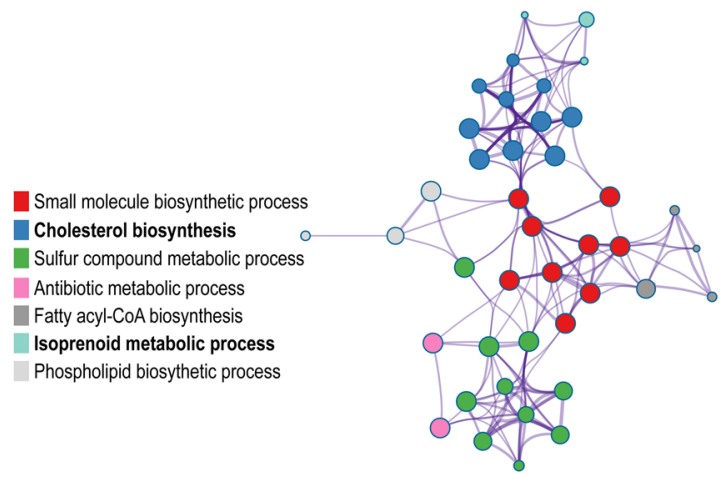

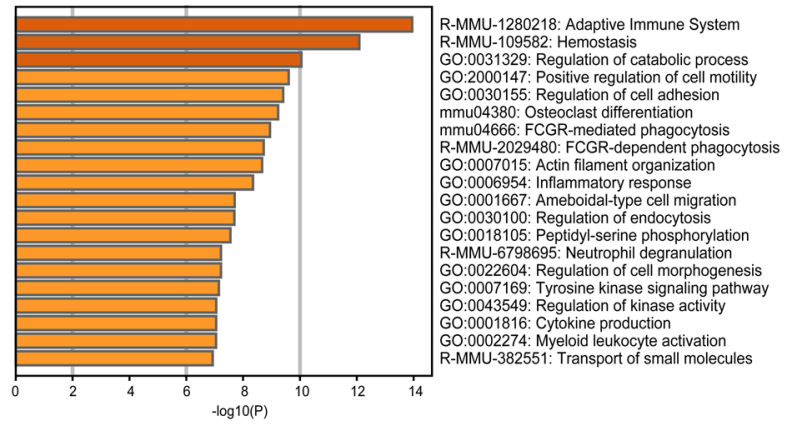

d Network of enriched terms accross HFD sensitive genes $(p<0.05)$ specifically in Ppara

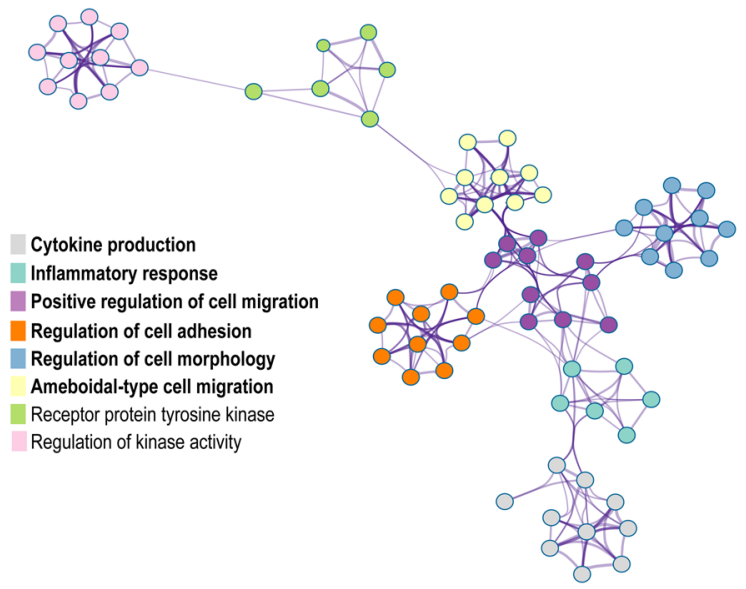

Figure 6. Specific effect of hepatocytic PPAR $\alpha$ and whole body PPAR $\alpha$ expression on liver gene expression in response to HFD-induced obesity. WT, $P$ pard ${ }^{\text {hep-l-}}$, and $P p a r \alpha^{-/}$mice were fed a control diet (CTRL) or a HFD for 10 weeks at $30^{\circ} \mathrm{C}$ (thermoneutrality). (a) Enriched terms across HFD sensitive genes $(\mathrm{p}<0.05)$ only in $P p a r^{\text {hep } \alpha-1-}$ mice (b) Network of enriched terms across HFD sensitive genes $(\mathrm{p}<0.05)$ only in Pparhep $\alpha-{ }^{--}$mice (c) Enriched terms across HFD sensitive genes $(\mathrm{p}<0.05)$ only in Ppar $^{-1-}$ mice $(\mathrm{d})$ Network of enriched terms across HFD sensitive genes $(\mathrm{p}<0.05)$ only in Ppar $^{-1-}$ mice.

increased relative abundance in HFD-fed $\mathrm{Ppar}^{-/-}$mice, suggesting that extra-hepatocytic PPAR $\alpha$ contributes predominantly to lipid remodelling during HFD-feeding. Cluster 1 also contains linoleic acid (C18:2n-6), which exhibits increased abundance in HFD-fed Ppard $^{-/}$mice, but also in HFD-fed Ppard ${ }^{\text {hep-l- }}$ mice. Lipids in cluster 2, such as the phospholipids PC36:3, PC28:6, PE38:4, and triglyceride TG C57 (Fig. 7c), are less abundant in HFD Ppard ${ }^{-1-}$ mice. Lipids in cluster 3, such as the palmitoleic acid (C16:1n-7) and PE32:1 (Fig. 7d), are less abundant in HFD mice from the three genotypes. Lipids in cluster 4 (Fig. 7e), such as the polyunsaturated fatty acids C20:4n-6 and C22:5n-3 are more abundant in WT mice from the CTRL diet group and reduced in the livers of mice fed a HFD.

Overall, this lipidomic profiling highlights that the hepatic lipidome depends on both the genotype and diet. Therefore, both hepatic Ppar $\alpha$ and whole body Ppar $\alpha$ deletions result in a specific lipidomic response to HFD feeding. However, whole body Ppard deficiency has a stronger influence on the effect of HFD-induced obesity on liver metabolic homeostasis.

\section{Discussion}

NAFLD is the hepatic manifestation of the obesity epidemic and represents a major public health issue worldwide $^{51}$. NAFLD ranges from benign steatosis to NASH and may promote liver fibrosis and cancer. Therefore, there is a great interest in drugs that could be used to cure NAFLD or reverse NASH before it promotes irreversible damage ${ }^{8}$. PPAR $\alpha$, and other PPAR isotypes represent targets currently being tested in clinical trials ${ }^{10,52,53}$. PPAR $\alpha$ is a ligand-activated nuclear receptor that plays a key role in the regulation of metabolic homeostasis by modulating the expression of rate-limiting enzymes involved in fatty acid degradation ${ }^{18-20}$. Preclinical studies in Ppar $\alpha$-null mice ${ }^{54}$ have shown that PPAR $\alpha$ protects from steatosis ${ }^{19,54}$. Moreover, several clinical lines of evidence indicate that PPAR $\alpha$ is also influential in human $\mathrm{NASH}^{55}$.

Most studies performed in vivo in Ppar $\alpha$-null mice have suggested that the mechanisms by which PPAR $\alpha$ protects from steatosis and NASH involve its ability to transactivate genes required for fatty acid catabolism ${ }^{38}$ and to repress a number of inflammatory genes ${ }^{39,41}$. Because PPAR $\alpha$ is expressed in many cell types and tissues with high fatty acid oxidation activity ${ }^{29-31,34}$, it is interesting to define in vivo the specific contribution of hepatocytic PPAR $\alpha$ in preventing NAFLD. 


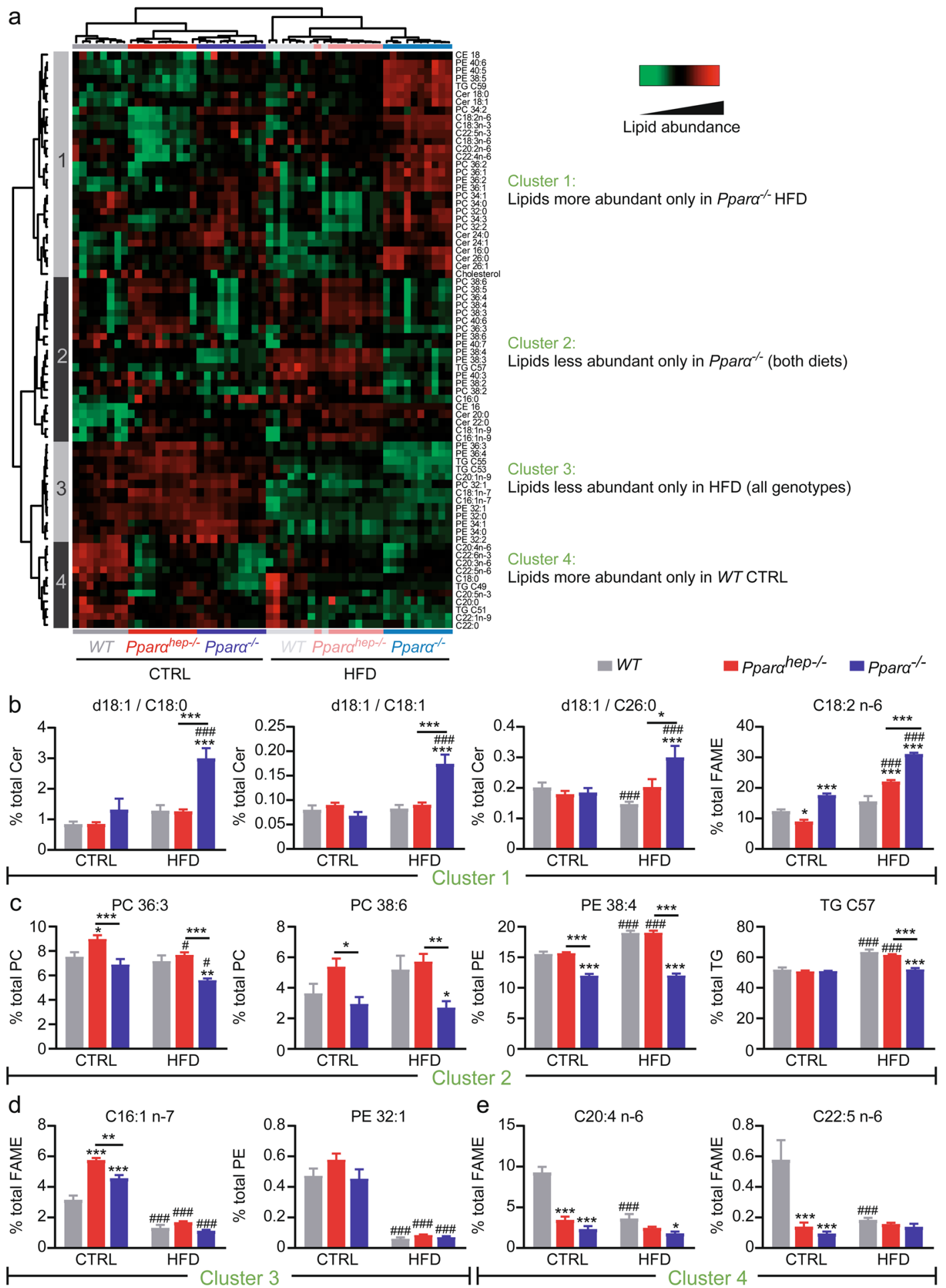

Figure 7. PPAR $\alpha$-dependent regulation of hepatic lipid homeostasis in response to HFD. WT, Pparq ${ }^{\text {hep-l- }}$, and $P_{\text {par }}{ }^{-1-}$ mice were fed a control diet (CTRL) or a HFD for 10 weeks at $30^{\circ} \mathrm{C}$ (thermoneutrality). (a) Heat map of data from hepatic lipid profiling in WT, Ppard ${ }^{\text {hep-l--}}$, and $P p a r \alpha^{-1-}$ mice exposed to HFD. Hierarchical clustering is also shown and defines four main lipid clusters. Representation of characteristic lipid species defining cluster 1 (b), 2 (c), 3 (d), and 4 (e). Data represent mean \pm SEM. \#, significant diet effect and $*$, significant genotype effect. ${ }^{\#}$ or $* \mathrm{p} \leq 0.05{ }^{\# \#}$ or $* * \mathrm{p} \leq 0.01{ }^{\# \# \#}$ or $* * * \mathrm{p} \leq 0.001$. Cer: ceramide; SM: sphingomyelin; TG: triglyceride; PC: phosphatidyl choline; PE: phosphatidyl ethanolamine; CE: cholesterol ester. 
When fed a regular diet, $P$ par ${ }^{-1-}$ mice are steatotic and overweight as previously reported ${ }^{26,38}$. When fed a HFD, they become even more steatotic and develop further liver inflammation ${ }^{39,41}$. Importantly, although $P$ par $\alpha$-null mice develop steatosis, they do not exhibit reduced glucose tolerance compared to $W T$ mice ${ }^{43}$. The data we obtained in Ppard ${ }^{\text {hep-l- }}$ mice fed a HFD indicate that the deletion of Ppar $\alpha$ in hepatocytes is sufficient to promote steatosis and inflammation. Therefore, hepatocyte-specific Ppar $\alpha$ deletion promotes steatosis and liver inflammation while dissociating steatosis from glucose intolerance as observed in ppard $^{-1-}$ mice ${ }^{42,43}$.

The mechanisms involved in the susceptibility to steatosis and protection from glucose intolerance likely involve the well-established role of PPAR $\alpha$ in the control of fatty acid transport and degradation ${ }^{18}$. The mechanisms by which hepatocyte Ppar $\alpha$ deficiency promotes NASH likely involve lipotoxic fat accumulation, including linoleic acid (C18:2n-6), which was recently identified as promoting NAFLD etiology in vivo ${ }^{56}$. Moreover, we extend previous observations and confirm the role of hepatocyte PPAR $\alpha$ in repressing the expression of inflammatory genes, such as those involved in the NF-kappa B pathway ${ }^{57,58}$. However, by comparing the HFD response in $P_{p a r \alpha^{-/-}}$and in $P_{p a r \alpha^{h e p-1-}}$ mice we observed differences in the expression of genes involved in inflammation (cell morphology, adhesion and migration) strongly suggesting that PPAR $\alpha$ activity might be important for liver immune cells activity in the context of obesity.

This study not only shows a specific effect of hepatocyte PPAR $\alpha$ activity, but also identifies several roles of non-hepatocytic PPAR $\alpha$. First, we confirmed our previous observations that, unlike Ppar $\alpha^{\text {hep-I- }}$ mice, $P p a r \alpha^{-/-}$ mice gain weight when fed a regular diet ${ }^{19}$. Moreover, because the current observations were made at thermoneutrality, this weight gain is not likely due to defective PPAR $\alpha$ expression and activity in the brown adipose tissue. In addition, by combining different large or medium scale analyses of the liver transcriptome and metabolome, we showed that the response to HFD was different in Ppar ${ }^{-1-}$ mice compared to Ppara ${ }^{\text {hep-1- }}$ mice, showing that extra-hepatocyte PPAR $\alpha$ mediates at least a part of the adaptive response to HFD. Since we observed significant differences in lipid metabolism between $P$ par $\alpha^{-/-}$and $P$ pard ${ }^{\text {hep-l- }}$ mice fed a HFD, our results are consistent with a possible extra-hepatic influence of PPAR $\alpha$ on whole body fatty acid and cholesterol homeostasis.

Taken together, our data demonstrate that hepatocyte-specific deletion of Ppar $\alpha$ promotes steatosis and inflammation in HFD-induced obesity and provide further pre-clinical evidence that hepatocyte PPAR $\alpha$ is a relevant direct target in NAFLD. Our data also suggest that extra-hepatic PPAR $\alpha$ plays a major homeostatic role in the control of the metabolic response to HFD. These data are in agreement with a recent study providing evidence that extrahepatic PPAR $\alpha$ activity such as in skeletal muscle and heart, may contribute to whole body fatty acid homeostasis ${ }^{59}$. Further research is required to investigate in which cells, other than hepatocytes, PPAR $\alpha$ regulates lipid metabolism in health and disease.

\section{Material and Methods}

Mice. All experiments were approved by the relevant animal care and use committee (CEEA-86, Ministry of Research and Higher Education, France); notification TOXCOM108, and conducted in accordance with the European directive 2010/63/UE.

$P$ par $\alpha^{\text {hep-l- }}$ animals were created at INRA's rodent facility (Toulouse, France) by mating the floxed-Ppar $\alpha$ mouse strain with C57BL/6 J albumin-Cre transgenic mice (a gift from Prof. Didier Trono, EPFL, Lausanne, Switzerland) to obtain albumin-Cre ${ }^{+-}$Ppard ${ }^{\text {flox/flox }}$ mice (i.e., Ppar $^{\text {hep-l- }}$ mice as described in $\left.{ }^{19}\right)$. The Ppar $\alpha$ deletion was confirmed with PCR and HotStar Taq DNA Polymerase ( $5 \mathrm{U} / \mu \mathrm{l}$, Qiagen) using the following primers: forward: 5' - AAAGCAGCCAGCTCTGTGTTGAGC-3' and reverse, $5^{\prime}$-TAGGTACCGTGGACTCAGAGCTAG-3'. The amplification conditions were as follows: $95^{\circ} \mathrm{C}$ for $15 \mathrm{~min}$, followed by 35 cycles of $94^{\circ} \mathrm{C}$ for $1 \mathrm{~min}, 65^{\circ} \mathrm{C}$ for $1 \mathrm{~min}$, and $72^{\circ} \mathrm{C}$ for $1 \mathrm{~min}$, and a final cycle of $72^{\circ} \mathrm{C}$ for $10 \mathrm{~min}$. This reaction produced $450-\mathrm{bp}, 915$-bp, and 1070-bp fragments, which represented the Ppar $\alpha$ sequence with an exon 4 deletion, the wild-type allele, and the floxed allele, respectively. The albumin-Cre allele was detected by PCR using the following primer pairs: CreU, 5' -AGGTGTAGAGAAGGCACTTAG-3' and CreD, 5' - CTAATCGCCATCTTCCAGCAGG-3'; G2lox7F, 5'-CCAATCCCTTGGTTCATGGTTGC- $3^{\prime}$ and G2lox7R, $5^{\prime}$-CGTAAGGCCCAAGGAAGTCCTGC-3').

Ppar $\alpha$-deficient C57BL/6 J mice $\left(\right.$ Ppar $\left.^{-1-}\right)$ were bred at INRA's transgenic rodent facility. Age-matched C57BL/6 J (provided by Charles River) were acclimated for 2 weeks to the local animal facility conditions prior to the experiment.

Mouse housing was controlled for temperature and light (12-h light/12-h dark). All mice were placed in a ventilated cabinet at the specific temperature of $30^{\circ} \mathrm{C}$ (thermoneutrality) throughout the experiment. All animals used in these experiments were male mice.

Diet. WT, $P$ pard ${ }^{-/-}$and Ppard ${ }^{\text {hep-l- }}$ mice were fed a standard diet (Safe 04 U8220G10R) until 8 weeks old, when the mice were fed a high fat diet (D12492, Research Diet) thought to induce mild hepatic lesions ${ }^{60}$. This HFD contains $60 \%$ calories from fat (lard), $20 \%$ calories from carbohydrates ( $7 \%$ sucrose) and $20 \%$ calories from proteins; or a chow diet (D12450J, Research Diet) containing 10\% calories from fat, 70\% calories from carbohydrates ( $7 \%$ sucrose) and $20 \%$ calories from protein during 10 weeks (until 20 weeks old). The estimated cholesterol content is: $0.014 \mathrm{~g} / \mathrm{kg}$ (chow diet) and $0.228 \mathrm{~g} / \mathrm{kg}$ (HFD diet). Experimental groups were designed as follows: WT CTRL, 8 mice; WT HFD, 8 mice; Ppard ${ }^{\text {hep }-1-}$ CTRL, 10 mice; Ppard $^{\text {hep }-1-}$ HFD, 9 mice; Ppard $^{-1-}$ CTRL, 10 mice; Ppard $^{-/-}$HFD, 10 mice.

Oral glucose tolerance test. Mice were fasted for $6 \mathrm{~h}$ and received an oral ( $2 \mathrm{~g} / \mathrm{kg}$ body weight) glucose load. Blood glucose was measured at the tail vein using an AccuCheck Performa glucometer (Roche Diagnostics) at $-15,0,15,30,45,60,90$, and 120 minutes.

Blood and tissue samples. Prior to sacrifice, blood was collected in EDTA-coated tubes (BD Microtainer, K2E tubes) from the submandibular vein. All mice were killed in a fed state. Plasma was collected by 
centrifugation $\left(1500 \times \mathrm{g}, 10 \mathrm{~min}, 4^{\circ} \mathrm{C}\right)$ and stored at $-80^{\circ} \mathrm{C}$. Following killing by cervical dislocation, the organs were removed, weighted, dissected and used for histological analysis or snap-frozen in liquid nitrogen and stored at $-80^{\circ} \mathrm{C}$.

Gene expression. Total cellular RNA was extracted with Tri reagent (Molecular Research Center). Total RNA samples $(2 \mu \mathrm{g})$ were then reverse-transcribed with the High-capacity cDNA Reverse Transcription Kit (Applied Biosystems) for real-time quantitative polymerase chain reaction (qPCR) analyses. The primers for Sybr Green assays are presented in Supplementary Table 1. Amplifications were performed on a Stratagene Mx3005P (Agilent Technology). The qPCR data were normalized to the level of the TATA-box binding protein (TBP) messenger RNA (mRNA) and analysed by the LinRegPCR v.11 software ${ }^{61}$.

Gene expression profiles were performed at the GeT-TRiX facility (GénoToul, Génopole Toulouse Midi-Pyrénées) using Agilent Sureprint G3 Mouse microarrays $(8 \times 60 \mathrm{~K}$, design 077809) following the manufacturer's instructions. For each sample, Cyanine-3 (Cy3) labeled cRNA was prepared from $200 \mathrm{ng}$ of total RNA using the One-Color Quick Amp Labeling kit (Agilent) according to the manufacturer's instructions, followed by Agencourt RNAClean XP (Agencourt Bioscience Corporation, Beverly, Massachusetts). Dye incorporation and cRNA yield were checked using Dropsense ${ }^{\mathrm{TM}} 96$ UV/VIS droplet reader (Trinean, Belgium). $600 \mathrm{ng}$ of Cy3-labelled cRNA were hybridized on the microarray slides following the manufacturer's instructions. Immediately after washing, the slides were scanned on Agilent G2505C Microarray Scanner using Agilent Scan Control A.8.5.1 software and fluorescence signal extracted using Agilent Feature Extraction software v10.10.1.1 with default parameters.

Microarray data and experimental details are available in NCBI's Gene Expression Omnibus ${ }^{62}$ and are accessible through GEO Series accession number GSE123354 (https://www.ncbi.nlm.nih.gov/geo/query/acc. cgi? acc $=$ GSE123354).

Histology. Formalin-fixed, paraffin-embedded liver tissue was sliced into $3 \mu \mathrm{m}$ sections and stained with haematoxylin and eosin (H\&E) for histopathological analysis. The staining was visualized with a Leica microscope DM4000 B equipped with a Leica DFC450 C camera. The H\&E-stained livers sections were analysed blindly for the steatosis and the inflammation (NAFLD activity score or NAS) according to Kleiner et al. ${ }^{49}$, Steatosis was measured depending on i) the percentage of liver cells containing fat (Grade 0 to 3); ii) the localisation of steatosis (Grade 0 to 3); and iii) the presence of microvesicular steatosis (Grade 0 to 1 ). The degree of inflammation was appreciated by counting the inflammatory foci into 10 distinct area at 200X for each liver slice (Grade 0 to 3 ). Values represent the mean of 10 fields/liver slice.

Biochemical analysis. Aspartate transaminase (AST), alanine transaminase (ALT), total cholesterol, LDL and HDL cholesterols were determined from plasma samples using a COBASMIRA + biochemical analyser (Anexplo facility).

Analysis of liver neutral lipids. Lipids were analysed as previously described ${ }^{20}$. Tissue samples were homogenized in methanol/5 mM EGTA $(2: 1, \mathrm{v} / \mathrm{v})$, and lipids (corresponding to an equivalent of $2 \mathrm{mg}$ tissue) extracted according to the Bligh-Dyer method ${ }^{63}$, with chloroform/methanol/water $(2.5: 2.5: 2 \mathrm{v} / \mathrm{v} / \mathrm{v})$, in the presence of the following internal standards: glyceryl trinonadecanoate, stigmasterol, and cholesteryl heptadecanoate (Sigma). Triglycerides, free cholesterol, and cholesterol esters were analysed by gas-liquid chromatography on a Focus Thermo Electron system equipped with a Zebron- 1 Phenomenex fused-silica capillary column $(5 \mathrm{~m}$, $0.25 \mathrm{~mm}$ i.d., $0.25 \mathrm{~mm}$ film thickness). The oven temperature was programmed to increase from 200 to $350^{\circ} \mathrm{C}$ at $5^{\circ} \mathrm{C} / \mathrm{min}$, and the carrier gas was hydrogen $(0.5 \mathrm{bar})$. The injector and detector temperatures were $315^{\circ} \mathrm{C}$ and $345^{\circ} \mathrm{C}$, respectively.

Liver fatty acid analysis. To measure all hepatic fatty acid methyl ester (FAME) molecular species, lipids that corresponded to an equivalent of $1 \mathrm{mg}$ of liver were extracted in the presence of the internal standard, glyceryl triheptadecanoate $(2 \mu \mathrm{g})$. The lipid extract was transmethylated with $1 \mathrm{ml} \mathrm{BF} 3$ in methanol (14\% solution; Sigma) and $1 \mathrm{ml}$ heptane for $60 \mathrm{~min}$ at $80^{\circ} \mathrm{C}$, and evaporated to dryness. The FAMEs were extracted with heptane/ water (2:1). The organic phase was evaporated to dryness and dissolved in $50 \mu \mathrm{l}$ ethyl acetate. A sample $(1 \mu \mathrm{l})$ of total FAME was analysed by gas-liquid chromatography (Clarus 600 Perkin Elmer system, with Famewax RESTEK fused silica capillary columns, $30-\mathrm{m} \times 0.32-\mathrm{mm}$ i.d., $0.25-\mu \mathrm{m}$ film thickness). The oven temperature was programmed to increase from $110^{\circ} \mathrm{C}$ to $220^{\circ} \mathrm{C}$ at a rate of $2^{\circ} \mathrm{C} / \mathrm{min}$, and the carrier gas was hydrogen $(7.25 \mathrm{psi})$. The injector and detector temperatures were $225^{\circ} \mathrm{C}$ and $245^{\circ} \mathrm{C}$, respectively.

Liver phospholipid and sphingolipid analysis. Chemicals and reagents. The liquid chromatography solvent, acetonitrile, was HPLC-grade and purchased from Acros Organics. Ammonium formate (>99\%) was supplied by Sigma Aldrich. Synthetic lipid standards (Cer d18:1/18:0, Cer d18:1/15:0, PE 12:0/12:0, PE 16:0/16:0, PC 13:0/13:0, PC 16:0/16:0, SM d18:1/18:0, SM d18:1/12:0) were purchased from Avanti Polar Lipids.

Lipid extraction. Lipids were extracted from the liver $(1 \mathrm{mg})$ as described by Bligh and Dyer in dichloromethane / methanol ( $2 \%$ acetic acid) / water (2.5:2.5:2 v/v/v). Internal standards were added (Cer d18:1/15:0, $16 \mathrm{ng} ; \mathrm{PE}$ 12:0/12:0, 180 ng; PC 13:0/13:0, 16 ng; SM d18:1/12:0, 16 ng; PI 16:0/17:0, 30 ng; PS 12:0/12:0, 156.25 ng). The solution was centrifuged at $1500 \mathrm{rpm}$ for $3 \mathrm{~min}$. The organic phase was collected and dried under azote, then dissolved in $50 \mu \mathrm{l} \mathrm{MeOH}$. Sample solutions were analysed using an Agilent 1290 UPLC system coupled to a G6460 triple quadripole spectrometer (Agilent Technologies). MassHunter software was used for data acquisition and analysis. A Kinetex HILIC column (Phenomenex, $50 \times 4.6 \mathrm{~mm}, 2.6 \mu \mathrm{m}$ ) was used for LC separations. The column temperature was maintained at $40^{\circ} \mathrm{C}$. Mobile phase A was acetonitrile and $\mathrm{B}$ was $10 \mathrm{mM}$ ammonium formate in 
water at $\mathrm{pH} 3.2$. The gradient was as follows: from $10 \%$ to $30 \% \mathrm{~B}$ in $10 \mathrm{~min}, 100 \% \mathrm{~B}$ from 10 to $12 \mathrm{~min}$, and then back to $10 \% \mathrm{~B}$ at $13 \mathrm{~min}$ for $1 \mathrm{~min}$ to re-equilibrate prior to the next injection. The flow rate of the mobile phase was $0.3 \mathrm{ml} / \mathrm{min}$, and the injection volume was $5 \mu \mathrm{l}$. An electrospray source was employed in positive (for Cer, PE, PC, and SM analysis) or negative ion mode (for PI and PS analysis). The collision gas was nitrogen. Needle voltage was set at $+4000 \mathrm{~V}$. Several scan modes were used. First, to obtain the naturally different masses of different species, we analysed cell lipid extracts with a precursor ion scan at $184 \mathrm{~m} / \mathrm{z}, 241 \mathrm{~m} / \mathrm{z}$, and $264 \mathrm{~m} / \mathrm{z}$ for PC/SM, PI, and Cer, respectively. We performed a neutral loss scan at 141 and $87 \mathrm{~m} / \mathrm{z}$ for PE and PS, respectively. The collision energy optimums for Cer, PE, PC, SM, PI, and PS were $25 \mathrm{eV}, 20 \mathrm{eV}, 30 \mathrm{eV}, 25 \mathrm{eV}, 45 \mathrm{eV}$, and $22 \mathrm{eV}$, respectively. The corresponding SRM transitions were used to quantify different phospholipid species for each class. Two MRM acquisitions were necessary, due to important differences between phospholipid classes. Data were treated with QqQ Quantitative (vB.05.00) and Qualitative analysis software (vB.04.00).

Metabolomic analyses by $1 \mathrm{H}$ nuclear magnetic resonance (NMR) spectroscopy. $\quad{ }^{1} \mathrm{H}$ NMR spectroscopy was performed on aqueous liver extracts prepared from liver samples (50-75 mg) homogenized in chloroform $/$ methanol/ $\mathrm{NaCl} 0.9 \%(2 / 1 / 0.6)$ containing $0.1 \%$ butyl hydroxytoluene and centrifuged at $5000 \times \mathrm{g}$ for $10 \mathrm{~min}$. The supernatant was collected, lyophilized, and reconstituted in $600 \mu \mathrm{l}$ of D2O containing $0.25 \mathrm{mM}$ TSP [3-(trimethylsilyl)propionic-(2,2,3,3-d4) acid sodium salt] as a chemical shift reference at 0 ppm. All $1 \mathrm{H} \mathrm{NMR}$ spectra were obtained on a Bruker DRX-600 Avance NMR spectrometer operating at $600.13 \mathrm{MHz}$ for $1 \mathrm{H}$ resonance frequency using an inverse detection $5 \mathrm{~mm} \mathrm{1H}-13 \mathrm{C}-15 \mathrm{~N}$ cryoprobe attached to a CryoPlatform (the preamplifier cooling unit). The $1 \mathrm{H}$ NMR spectra were acquired at $300 \mathrm{~K}$ with a $1 \mathrm{D}$ NOESY-presat sequence (relaxation delay $-90^{\circ}$-t $-90^{\circ}$-tm- $90^{\circ}$-acquisition). A total of 128 transients were acquired into a spectrum with $20 \mathrm{ppm}$ width, $32 \mathrm{k}$ data points, a relaxation delay of $2.0 \mathrm{~s}$, and a mixing delay of $100 \mathrm{~ms}$. All $1 \mathrm{H}$ spectra were zero-filled to $64 \mathrm{k}$ points and subjected to $0.3 \mathrm{~Hz}$ exponential line broadening before Fourier transformation. The spectra were phase and baseline corrected and referenced to TSP $(1 \mathrm{H}, \mathrm{d} 0.0 \mathrm{ppm})$ using Bruker Topspin 2.1 software (Bruker $\mathrm{GmbH}$, Karlsruhe, Germany). Multivariate analysis of metabolomic data was performed.

Statistical analysis. Biochemical, qPCR and phenotypic data were analysed using and graphpad software. Differential effects were assessed on log2 transformed data by performing ANOVA followed by Sidak post-hoc tests. p-values $<0.05$ were considered significant.

Hierarchical clustering of lipid quantification data was performed using R (R Development Core Team, 2018) with the heatmap. 2 function from the package, gplots. Data were log 2 transformed, then centred and scaled by lipid. Hierarchical clustering was applied to the samples and the lipids using 1-Pearson correlation coefficient as distance and Ward's criterion (Ward.D2) for agglomeration. All the data represented on the heat map had adjusted p-values $<0.05$ for one or more comparisons performed with an analysis of variance.

Microarray data were analyzed using $\mathrm{R}$ and Bioconductor packages (www.bioconductor.org, v 3.0), as described in GEO accession GSE123354. Raw data (median signal intensity) were filtered, log2 transformed, corrected for batch effects (microarray washing bath) and normalized using quantile method ${ }^{64}$.

A model was fitted using the limma lmFit function ${ }^{65}$ considering array weights using arrayWeights function. Pair-wise comparisons between biological conditions were applied using specific contrasts. A correction for multiple testing was applied using Benjamini-Hochberg procedure ${ }^{66}$ for False Discovery Rate (FDR). Probes with $\mathrm{FDR} \leq 0.05$ were considered to be differentially expressed between conditions.

In addition to the differential analysis, a multivariate exploratory analysis was performed. A Sparse Partial Least Squares Discriminant Analysis ${ }^{67}$ (sPLS-DA) was conducted using mixOmics package ${ }^{68}$ under to select the most discriminative variables (genes) that help classify the samples according to their experimental conditions among their expression values. Twenty iterations of 5-fold cross-validation was used to evaluate the model performance for the selection of the most informative components ( 6 components chosen) using all the variables (PLS-DA). Then a "sparse" PLS-DA model was parametrized selecting the first 100, 120, 80, 40, 100 and 20 (chosen according the performance results of 20 iterations of 5 -fold cross-validations) most discriminant variables on the components 1 to 6 respectively.

Hierarchical clustering was applied to the samples and the differentially expressed probes using 1-Pearson correlation coefficient as distance and Ward's criterion for agglomeration. The clustering results are illustrated as a heatmap of expression signals. Gene network and enrichment of KEGG pathways was either performed using the online software STRING V.11 ${ }^{69}$ or Metascape ${ }^{70}$. Correlation graphic chart was generated using the chart correlation function from the Performance Analytics package.

Received: 6 February 2019; Accepted: 30 March 2020;

Published online: 16 April 2020

\section{References}

1. Younossi, Z. M. et al. Global epidemiology of nonalcoholic fatty liver disease-Meta-analytic assessment of prevalence, incidence, and outcomes. Hepatology 64, 73-84, https://doi.org/10.1002/hep.28431 (2016).

2. Samuel, V. T. \& Shulman, G. I. Nonalcoholic Fatty Liver Disease as a Nexus of Metabolic and Hepatic Diseases. Cell Metab 27, 22-41, https://doi.org/10.1016/j.cmet.2017.08.002 (2018)

3. Donnelly, K. L. et al. Sources of fatty acids stored in liver and secreted via lipoproteins in patients with nonalcoholic fatty liver disease. J Clin Invest 115, 1343-1351, https://doi.org/10.1172/jci23621 (2005).

4. Hernández, E. Á. et al. Acute dietary fat intake initiates alterations in energy metabolism and insulin resistance. The Journal of clinical investigation 127, 695-708, https://doi.org/10.1172/JCI89444 (2017).

5. Tamura, S. \& Shimomura, I. Contribution of adipose tissue and de novo lipogenesis to nonalcoholic fatty liver disease. J Clin Invest 115, 1139-1142, https://doi.org/10.1172/jci24930 (2005) 
6. Marra, F., Gastaldelli, A., Svegliati Baroni, G., Tell, G. \& Tiribelli, C. Molecular basis and mechanisms of progression of nonalcoholic steatohepatitis. Trends Mol Med 14, 72-81, https://doi.org/10.1016/j.molmed.2007.12.003 (2008).

7. Hebbard, L. \& George, J. Animal models of nonalcoholic fatty liver disease. Nat Rev Gastroenterol Hepatol 8, 35-44, https://doi. org/10.1038/nrgastro.2010.191 (2011).

8. Rotman, Y. \& Sanyal, A. J. Current and upcoming pharmacotherapy for non-alcoholic fatty liver disease. Gut 66, 180-190, https:// doi.org/10.1136/gutjnl-2016-312431 (2017).

9. Wong, V. W., Adams, L. A., de Ledinghen, V., Wong, G. L. \& Sookoian, S. Noninvasive biomarkers in NAFLD and NASH - current progress and future promise. Nat Rev Gastroenterol Hepatol 15, 461-478, https://doi.org/10.1038/s41575-018-0014-9 (2018).

10. Gross, B., Pawlak, M., Lefebvre, P. \& Staels, B. PPARs in obesity-induced T2DM, dyslipidaemia and NAFLD. Nat Rev Endocrinol 13, 36-49, https://doi.org/10.1038/nrendo.2016.135 (2017).

11. Krey, G. et al. Fatty acids, eicosanoids, and hypolipidemic agents identified as ligands of peroxisome proliferator-activated receptors by coactivator-dependent receptor ligand assay. Mol Endocrinol 11, 779-791, https://doi.org/10.1210/mend.11.6.0007 (1997).

12. Devchand, P. R. et al. The PPARalpha-leukotriene B4 pathway to inflammation control. Nature 384, 39-43, https://doi. org/10.1038/384039a0 (1996).

13. Chakravarthy, M. V. et al. Identification of a physiologically relevant endogenous ligand for PPARalpha in liver. Cell 138, 476-488, https://doi.org/10.1016/j.cell.2009.05.036 (2009).

14. Dubois, V., Eeckhoute, J., Lefebvre, P. \& Staels, B. Distinct but complementary contributions of PPAR isotypes to energy homeostasis. J Clin Invest 127, 1202-1214, https://doi.org/10.1172/jci88894 (2017).

15. Ip, E., Farrell, G., Hall, P., Robertson, G. \& Leclercq, I. Administration of the potent PPARalpha agonist, Wy-14,643, reverses nutritional fibrosis and steatohepatitis in mice. Hepatology 39, 1286-1296, https://doi.org/10.1002/hep.20170 (2004).

16. Staels, B. et al. Hepatoprotective effects of the dual peroxisome proliferator-activated receptor alpha/delta agonist, GFT505, in rodent models of nonalcoholic fatty liver disease/nonalcoholic steatohepatitis. Hepatology 58, 1941-1952, https://doi.org/10.1002/ hep.26461 (2013).

17. Braissant, O., Foufelle, F., Scotto, C., Dauca, M. \& Wahli, W. Differential expression of peroxisome proliferator-activated receptors (PPARs): tissue distribution of PPAR-alpha, -beta, and -gamma in the adult rat. Endocrinology 137, 354-366, https://doi. org/10.1210/endo.137.1.8536636 (1996).

18. Kersten, S. Integrated physiology and systems biology of PPARalpha. Mol Metab 3, 354-371, https://doi.org/10.1016/j. molmet.2014.02.002 (2014)

19. Montagner, A. et al. Liver PPARalpha is crucial for whole-body fatty acid homeostasis and is protective against NAFLD. Gut 65, 1202-1214, https://doi.org/10.1136/gutjnl-2015-310798 (2016).

20. Regnier, M. et al. Insights into the role of hepatocyte PPARalpha activity in response to fasting. Mol Cell Endocrinol 471, 75-88, https://doi.org/10.1016/j.mce.2017.07.035 (2018).

21. Goldstein, I. \& Hager, G. L. Transcriptional and Chromatin Regulation during Fasting - The Genomic Era. Trends Endocrinol Metab 26, 699-710, https://doi.org/10.1016/j.tem.2015.09.005 (2015).

22. Hondares, E. et al. Hepatic FGF21 expression is induced at birth via PPARalpha in response to milk intake and contributes to thermogenic activation of neonatal brown fat. Cell Metab 11, 206-212, https://doi.org/10.1016/j.cmet.2010.02.001 (2010).

23. Cotter, D. G., Ercal, B., d'Avignon, D. A., Dietzen, D. J. \& Crawford, P. A. Impairments of hepatic gluconeogenesis and ketogenesis in PPARalpha- deficient neonatal mice. Am J Physiol Endocrinol Metab 307, E176-185, https://doi.org/10.1152/ajpendo.00087.2014 (2014).

24. Rando, G. et al. Glucocorticoid receptor-PPARalpha axis in fetal mouse liver prepares neonates for milk lipid catabolism. Elife 5, https://doi.org/10.7554/eLife.11853 (2016).

25. Kersten, S. et al. Peroxisome proliferator-activated receptor alpha mediates the adaptive response to fasting. J Clin Invest 103, 1489-1498, https://doi.org/10.1172/jci6223 (1999).

26. Kroetz, D. L., Yook, P., Costet, P., Bianchi, P. \& Pineau, T. Peroxisome proliferator-activated receptor alpha controls the hepatic CYP4A induction adaptive response to starvation and diabetes. J Biol Chem 273, 31581-31589, https://doi.org/10.1074/ jbc.273.47.31581 (1998).

27. Leone, T. C., Weinheimer, C. J. \& Kelly, D. P. A critical role for the peroxisome proliferator-activated receptor alpha (PPARalpha) in the cellular fasting response: the PPARalpha-null mouse as a model of fatty acid oxidation disorders. Proc Natl Acad Sci USA 96, 7473-7478, https://doi.org/10.1073/pnas.96.13.7473 (1999).

28. Polizzi, A. et al. Hepatic Fasting-Induced PPARalpha Activity Does Not Depend on Essential Fatty Acids. Int J Mol Sci 17, https:// doi.org/10.3390/ijms17101624 (2016).

29. Liu, S. et al. A diurnal serum lipid integrates hepatic lipogenesis and peripheral fatty acid use. Nature 502, 550-554, https://doi. org/10.1038/nature12710 (2013).

30. Tsuchida, A. et al. Peroxisome proliferator-activated receptor (PPAR)alpha activation increases adiponectin receptors and reduces obesity-related inflammation in adipose tissue: comparison of activation of PPARalpha, PPARgamma, and their combination. Diabetes 54, 3358-3370, https://doi.org/10.2337/diabetes.54.12.3358 (2005).

31. Goto, T. et al. Activation of peroxisome proliferator-activated receptor-alpha stimulates both differentiation and fatty acid oxidation in adipocytes. J Lipid Res 52, 873-884, https://doi.org/10.1194/jlr.M011320 (2011).

32. Barquissau, V. et al. White-to-brite conversion in human adipocytes promotes metabolic reprogramming towards fatty acid anabolic and catabolic pathways. Mol Metab 5, 352-365, https://doi.org/10.1016/j.molmet.2016.03.002 (2016).

33. Defour, M. et al. The Peroxisome Proliferator-Activated Receptor alpha is dispensable for cold-induced adipose tissue browning in mice. Mol Metab 10,39-54, https://doi.org/10.1016/j.molmet.2018.01.023 (2018).

34. Bunger, M. et al. Genome-wide analysis of PPARalpha activation in murine small intestine. Physiol Genomics 30, 192-204, https:// doi.org/10.1152/physiolgenomics.00198.2006 (2007).

35. Haemmerle, G. et al. ATGL-mediated fat catabolism regulates cardiac mitochondrial function via PPAR-alpha and PGC-1. Nat Med 17, 1076-1085, https://doi.org/10.1038/nm.2439 (2011).

36. Sugden, M. C., Bulmer, K., Gibbons, G. F. \& Holness, M. J. Role of peroxisome proliferator-activated receptor-alpha in the mechanism underlying changes in renal pyruvate dehydrogenase kinase isoform 4 protein expression in starvation and after refeeding. Arch Biochem Biophys 395, 246-252, https://doi.org/10.1006/abbi.2001.2586 (2001)

37. Costet, P. et al. Peroxisome proliferator-activated receptor alpha-isoform deficiency leads to progressive dyslipidemia with sexually dimorphic obesity and steatosis. J Biol Chem 273, 29577-29585, https://doi.org/10.1074/jbc.273.45.29577 (1998).

38. Abdelmegeed, M. A. et al. PPARalpha expression protects male mice from high fat-induced nonalcoholic fatty liver. J Nutr 141, 603-610, https://doi.org/10.3945/jn.110.135210 (2011)

39. Patsouris, D., Reddy, J. K., Muller, M. \& Kersten, S. Peroxisome proliferator-activated receptor alpha mediates the effects of high-fat diet on hepatic gene expression. Endocrinology 147, 1508-1516, https://doi.org/10.1210/en.2005-1132 (2006).

40. Stienstra, R. et al. Peroxisome proliferator-activated receptor alpha protects against obesity-induced hepatic inflammation. Endocrinology 148, 2753-2763, https://doi.org/10.1210/en.2007-0014 (2007).

41. Ip, E. et al. Central role of PPARalpha-dependent hepatic lipid turnover in dietary steatohepatitis in mice. Hepatology 38, 123-132, https://doi.org/10.1053/jhep.2003.50307 (2003).

42. Guerre-Millo, M. et al. PPAR-alpha-null mice are protected from high-fat diet-induced insulin resistance. Diabetes 50, 2809-2814, https://doi.org/10.2337/diabetes.50.12.2809 (2001). 
43. Patsouris, D. et al. PPARalpha governs glycerol metabolism. J Clin Invest 114, 94-103, https://doi.org/10.1172/jci20468 (2004).

44. Badman, M. K. et al. Hepatic fibroblast growth factor 21 is regulated by PPARalpha and is a key mediator of hepatic lipid metabolism in ketotic states. Cell Metab 5, 426-437, https://doi.org/10.1016/j.cmet.2007.05.002 (2007).

45. Iroz, A. et al. A Specific ChREBP and PPARalpha Cross-Talk Is Required for the Glucose- Mediated FGF21 Response. Cell Rep 21, 403-416, https://doi.org/10.1016/j.celrep.2017.09.065 (2017).

46. Kharitonenkov, A. \& DiMarchi, R. FGF21 Revolutions: Recent Advances Illuminating FGF21 Biology and Medicinal Properties. Trends Endocrinol Metab 26, 608-617, https://doi.org/10.1016/j.tem.2015.09.007 (2015).

47. Fisher, F. M. et al. Fibroblast growth factor 21 limits lipotoxicity by promoting hepatic fatty acid activation in mice on methionine and choline-deficient diets. Gastroenterology 147, 1073-1083.e1076, https://doi.org/10.1053/j.gastro.2014.07.044 (2014).

48. Singhal, G. et al. Deficiency of fibroblast growth factor 21 (FGF21) promotes hepatocellular carcinoma (HCC) in mice on a long term obesogenic diet. Mol Metab 13, 56-66, https://doi.org/10.1016/j.molmet.2018.03.002 (2018).

49. Kleiner, D. E. et al. Design and validation of a histological scoring system for nonalcoholic fatty liver disease. Hepatology 41, 1313-1321, https://doi.org/10.1002/hep.20701 (2005).

50. van Diepen, J. A. et al. PPAR-alpha dependent regulation of vanin-1 mediates hepatic lipid metabolism. J Hepatol 61, 366-372, https://doi.org/10.1016/j.jhep.2014.04.013 (2014).

51. Estes, C., Razavi, H., Loomba, R., Younossi, Z. \& Sanyal, A. J. Modeling the epidemic of nonalcoholic fatty liver disease demonstrates an exponential increase in burden of disease. Hepatology 67, 123-133, https://doi.org/10.1002/hep.29466 (2018).

52. Wettstein, G. et al. The new-generation pan-peroxisome proliferator-activated receptor agonist IVA337 protects the liver from metabolic disorders and fibrosis. Hepatol Commun 1, 524-537, https://doi.org/10.1002/hep4.1057 (2017).

53. Ratziu, V. et al. Elafibranor, an Agonist of the Peroxisome Proliferator-Activated Receptor-alpha and -delta, Induces Resolution of Nonalcoholic Steatohepatitis Without Fibrosis Worsening. Gastroenterology 150, 1147-1159.e1145, https://doi.org/10.1053/j. gastro.2016.01.038 (2016)

54. Lee, S. S. et al. Targeted disruption of the alpha isoform of the peroxisome proliferator- activated receptor gene in mice results in abolishment of the pleiotropic effects of peroxisome proliferators. Mol Cell Biol 15, 3012-3022, https://doi.org/10.1128/ mcb.15.6.3012 (1995).

55. Francque, S. et al. PPARalpha gene expression correlates with severity and histological treatment response in patients with nonalcoholic steatohepatitis. J Hepatol 63, 164-173, https://doi.org/10.1016/j.jhep.2015.02.019 (2015).

56. Ma, C. et al. NAFLD causes selective CD4(+) T lymphocyte loss and promotes hepatocarcinogenesis. Nature 531, 253-257, https:// doi.org/10.1038/nature16969 (2016)

57. Mansouri, R. M., Bauge, E., Staels, B. \& Gervois, P. Systemic and distal repercussions of liver-specific peroxisome proliferatoractivated receptor-alpha control of the acute-phase response. Endocrinology 149, 3215-3223, https://doi.org/10.1210/en.2007-1339 (2008).

58. Pawlak, M., Lefebvre, P. \& Staels, B. Molecular mechanism of PPARalpha action and its impact on lipid metabolism, inflammation and fibrosis in non-alcoholic fatty liver disease. J Hepatol 62, 720-733, https://doi.org/10.1016/j.jhep.2014.10.039 (2015).

59. Brocker, C. N. et al. Extrahepatic PPARalpha modulates fatty acid oxidation and attenuates fasting-induced hepatosteatosis in mice. J Lipid Res 59, 2140-2152, https://doi.org/10.1194/jlr.M088419 (2018).

60. Farrell, G. et al. Mouse Models of Nonalcoholic Steatohepatitis: Toward Optimization of Their Relevance to Human Nonalcoholic Steatohepatitis. Hepatology (Baltimore, Md.) 69, 2241-2257, https://doi.org/10.1002/hep.30333 (2019).

61. Ruijter, J. M. et al. Amplification efficiency: linking baseline and bias in the analysis of quantitative PCR data. Nucleic Acids Res 37, e45, https://doi.org/10.1093/nar/gkp045 (2009).

62. Edgar, R., Domrachev, M. \& Lash, A. E. Gene Expression Omnibus: NCBI gene expression and hybridization array data repository. Nucleic Acids Res 30, 207-210, https://doi.org/10.1093/nar/30.1.207 (2002).

63. Bligh, E. G. \& Dyer, W. J. A rapid method of total lipid extraction and purification. Can J Biochem Physiol 37, 911-917, https://doi. org/10.1139/059-099 (1959).

64. Bolstad, B. M., Irizarry, R. A., Astrand, M. \& Speed, T. P. A comparison of normalization methods for high density oligonucleotide array data based on variance and bias. Bioinformatics 19, 185-193, https://doi.org/10.1093/bioinformatics/19.2.185 (2003).

65. Ritchie, M. E. et al. limma powers differential expression analyses for RNA-sequencing and microarray studies. Nucleic Acids Res 43, e47, https://doi.org/10.1093/nar/gkv007 (2015).

66. Benjamini, Y. \& Hochberg, Y. Controlling the False Discovery Rate: A Practical and Powerful Approach to Multiple Testing. Royal statistical society 57, 289-300 (1995).

67. Le Cao, K. A., Boitard, S. \& Besse, P. Sparse PLS discriminant analysis: biologically relevant feature selection and graphical displays for multiclass problems. BMC Bioinformatics 12, 253, https://doi.org/10.1186/1471-2105-12-253 (2011).

68. Le Cao, K. A. et al. MixMC: A Multivariate Statistical Framework to Gain Insight into Microbial Communities. PLoS One 11, e0160169, https://doi.org/10.1371/journal.pone.0160169 (2016).

69. Szklarczyk, D. et al. STRING v10: protein-protein interaction networks, integrated over the tree of life. Nucleic Acids Res 43, D447-452, https://doi.org/10.1093/nar/gku1003 (2015).

70. Zhou, Y. et al. Metascape provides a biologist-oriented resource for the analysis of systems-level datasets. Nat Commun 10, 1523-1523, https://doi.org/10.1038/s41467-019-09234-6 (2019).

\section{Acknowledgements}

We thank all members of the EZOP staff for their careful help from the early start of this project. We thank Léa Morra-Charrot and Laurent Monbrun from Anexplo for their excellent work on plasma biochemistry. We thank the staff from the Genotoul: Anexplo, GeT-TRiX and Metatoul-Lipidomic facilities. The authors wish to thank Pr Daniel Metzger, Pr Pierre Chambon (IGBMC, Illkirch, France) and the staff of the Mouse Clinical Institute (Illkirch, France) for their critical support in this project. We thank Pr Didier Trono (EPFL, Lausanne, Switzerland) for providing the Albumin-Cre mice. We thank Dr Joel Haas, Pr Bart Staels and Dr Thierry Pineau for constructive discussions. We thank Dr Thierry Pineau for providing us with Ppar $\alpha$-null mice. M.R. is supported by a PhD grant from Université Paul Sabatier (Toulouse). W.W. is supported by the Lee Kong Chian School of Medicine, Nanyang Technological University Singapore start-up Grant. This work was funded by ANR "Fumolip" and "Hepadialogue" (to C.P,. D.L., N.L. and H.G.). S.E.-S., N.L., A.M. and H.G. are supported by the JPI HDHL - FATMAL. A.M., W.W., D.L., N.L. and H.G. were supported by Région Occitanie.

\section{Author contributions}

S.S., C.L., A.F., Y.L., E.F., F.L., C.N., C.B., V.B., E.M., J.B.M., A.B., T.A.S., C.C., M.T.F., S.E.S. contributed to experiments, to data analysis and to provide critical technical support. D.L., C.P., W.W., N.L. contributed to design the project, to supervise experiments and to write the paper. M.R., A.P., H.G., A.M. designed experiments, performed experiments, analysed the data and wrote the paper. 


\section{Competing interests}

The authors declare no competing interests.

\section{Additional information}

Supplementary information is available for this paper at https://doi.org/10.1038/s41598-020-63579-3.

Correspondence and requests for materials should be addressed to H.G. or A.M.

Reprints and permissions information is available at www.nature.com/reprints.

Publisher's note Springer Nature remains neutral with regard to jurisdictional claims in published maps and institutional affiliations.

(c) (i) Open Access This article is licensed under a Creative Commons Attribution 4.0 International License, which permits use, sharing, adaptation, distribution and reproduction in any medium or format, as long as you give appropriate credit to the original author(s) and the source, provide a link to the Creative Commons license, and indicate if changes were made. The images or other third party material in this article are included in the article's Creative Commons license, unless indicated otherwise in a credit line to the material. If material is not included in the article's Creative Commons license and your intended use is not permitted by statutory regulation or exceeds the permitted use, you will need to obtain permission directly from the copyright holder. To view a copy of this license, visit http://creativecommons.org/licenses/by/4.0/.

(C) The Author(s) 2020 